Portland State University

PDXScholar

\title{
Promoting Environmental Justice Populations'
} Access to Opportunities with Suburban Boomtowns: An Interdisciplinary Mixed-Methods Approach to Addressing Infrastructure Needs

Jandel Crutchfield

University of Texas at Arlington

Courtney Cronley

University of Texas at Arlington

Kate Hyun

University of Texas at Arlington

Erin Findley

University of Texas at Arlington

Follow this and additional works at: https://pdxscholar.library.pdx.edu/trec_reports

Mohrdad Arabi

S., Perstity d d Commons

Let us know how access to this document benefits you.

\section{Recommended Citation}

Crutchfield, J., Cronley, C., Hyun, K., Findley, E., Arabi, M. (2019). Promoting Environmental Justice Populations' Access to Opportunities with Suburban Boomtowns: An Interdisciplinary Mixed-Methods Approach to Addressing Infrastructure Needs. NITC-RR-1263. Portland, OR: Transportation Research and Education Center (TREC), 2020.https://dx.doi.org/10.15760/trec.243

This Report is brought to you for free and open access. It has been accepted for inclusion in TREC Final Reports by an authorized administrator of PDXScholar. Please contact us if we can make this document more accessible: pdxscholar@pdx.edu. 

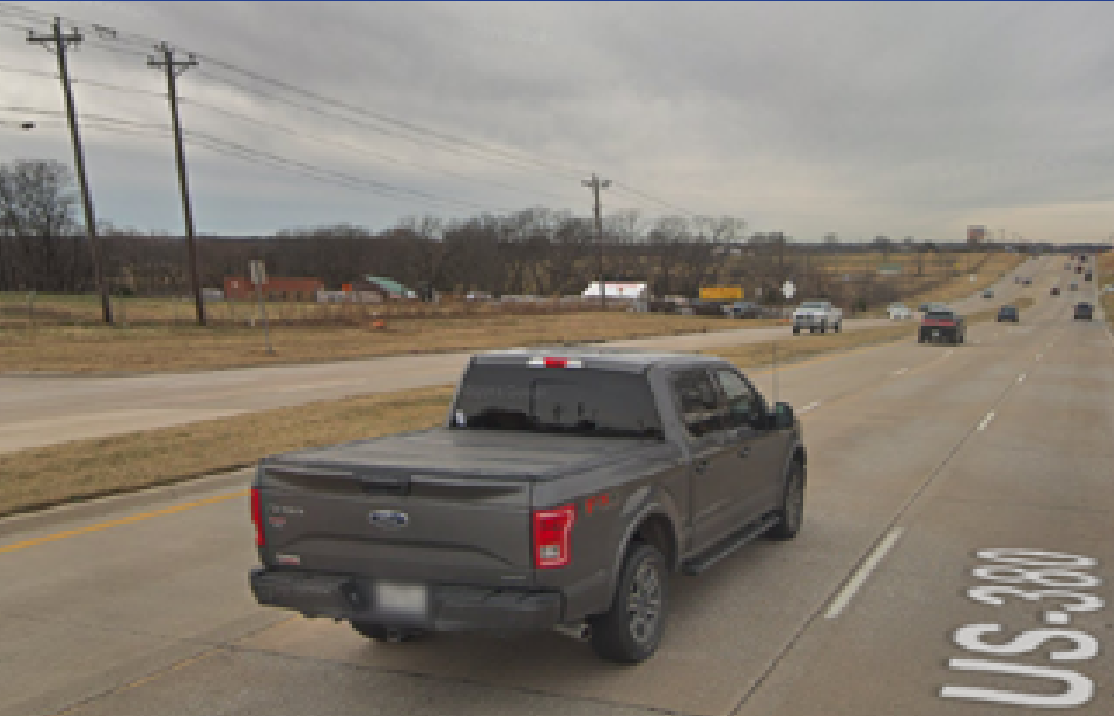

\section{Promoting Environmental Justice Populations' Access to Opportunities with Suburban} Boomtowns: An Interdisciplinary Mixed-Methods Approach to Addressing Infrastructure Needs Jandel Crutchfield, Ph.D. Courtney Cronley, Ph.D. Kate Hyun, Ph.D. Erin Findley Mehrdad Arabi 


\section{PROMOTING ENVIRONMENTAL JUSTICE POPULATIONS' ACCESS TO OPPORTUNITIES WITHIN SUBURBAN BOOMTOWNS}

AN INTERDISCIPLINARY MIXED-METHODS APPROACH TO ADDRESSING INFRASTRUCTURE NEEDS

Final Report

NITC-RR-1263

by

Jandel Crutchfield

Courtney Cronley

Kate Hyun

Erin Findley

Mehrdad Arabi

University of Texas at Arlington

for

National Institute for Transportation and Communities (NITC)

P.O. Box 751

Portland, OR 97207
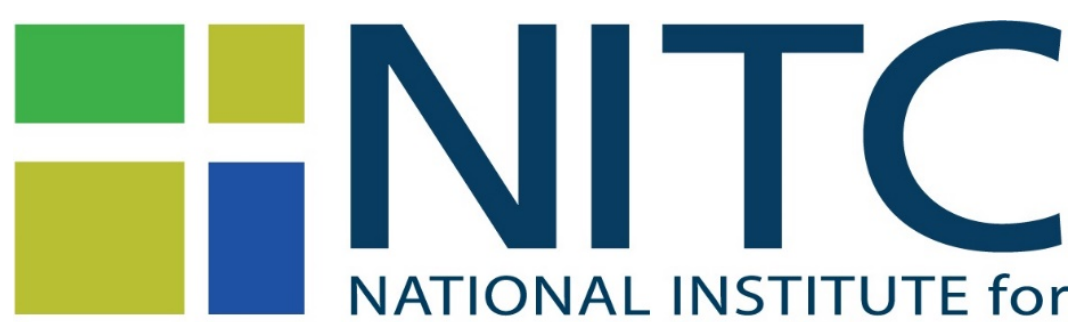

NATIONAL INSTITUTE for

TRANSPORTATION and COMMUNITIES

February 2020 
Technical Report Documentation Page

1. Report No.

NITC-RR-1263

2. Government Accession No.

3. Recipient's Catalog No.

4. Title and Subtitle

Promoting Environmental Justice Populations' Access to

Opportunities with Suburban Boomtowns: An Interdisciplinary

Mixed-Methods Approach to Addressing Infrastructure Needs

7. Author(s) Jandel Crutchfield, Courtney Cronley, Kate Hyun, Erin Findley,

Mehrdad Arabi

9. Performing Organization Name and Address

University of Texas at Arlington

211 South Cooper Street

Arlington TX 76019

12. Sponsoring Agency Name and Address

National Institute for Transportation and Communities (NITC)

P.O. Box 751

Portland, Oregon 97207

6. Performing Organization Code

8. Performing Organization Report No.

10. Work Unit No. (TRAIS)

11. Contract or Grant No.

13. Type of Report and Period

Covered

Final Report

November 2018-October 2019

15. Supplementary Notes

14. Sponsoring Agency Code

\section{Abstract}

This study used a community-engaged interdisciplinary approach to assess the gaps between economic growth and transportation infrastructure development, and the impact of potential gaps on access to opportunities for environmental justice populations within North Central Texas, where population growth has increased over $100 \%$ since 2000 . The interdisciplinary team, comprised of social work and civil engineering researchers, in partnership with the regional homeless coalition, measured residents' perspectives of the economic growth in the area over the past decade, the extent to which transportation infrastructure has matched the economic growth, and the implications for access to affordable quality housing, employment, quality public education, as well as engagement in cultural and social activities. The team utilized a mixed-methods (focus groups and survey data), exploratory design to collect responses from a diverse sampling frame. The researchers compared results across environmental justice populations, and those who may have greater access to private transportation, e.g., personal vehicles. Social work led the community-engaged component of the social science data collection and civil engineering conducted statistical modeling related to mapping census data onto transportation access. The study results produced an infrastructure profile for the region, in which increased infrastructure from toll ways have improved job and population density, but with major challenges for usage of public transit. The results can inform public policies that support targeted transportation infrastructure development. Moreover, study results can inform the knowledge base regarding the relationship between economic growth and transportation infrastructure and how to improve their co-development, with a particular emphasis on the planning needs of environmental justice populations.

17. Key Words

\begin{tabular}{|l|l|}
\hline 19. Security Classification (of this report) & $\begin{array}{l}20 . \text { Security Classification (of } \\
\text { this page) } \\
\text { Unclassified }\end{array}$ \\
\hline
\end{tabular}

18. Distribution Statement No restrictions. Copies available from NITC: www.nitc-utc.net 


\section{ACKNOWLEDGEMENTS}

This project was funded by the National Institute for Transportation and Communities (NITC; grant number 1263 a U.S. DOT University Transportation Center, and the National Science Foundation (NSF; Grant number BCS-123456)."

The authors would like to acknowledge additional support from the School of Social Work, Department of Civil Engineering, and the Office of Research at the University of Texas at Arlington.

\section{DISCLAIMER}

The contents of this report reflect the views of the authors, who are solely responsible for the facts and the accuracy of the material and information presented herein. This document is disseminated under the sponsorship of the U.S. Department of Transportation University Transportation Centers Program and the University of Texas at Arlington in the interest of information exchange. The U.S. Government and the University of Texas at Arlington assume no liability for the contents or use thereof. The contents do not necessarily reflect the official views of the U.S. Government and the University of Texas at Arlington]. This report does not constitute a standard, specification, or regulation.

\section{RECOMMENDED CITATION}

Crutchfield, Jandel; Cronley, Courtney; Hyun, Kate; Findley, Erin, Arabi, Mehrdad. (2019). Promoting Environmental Justice Populations' Access to Opportunities with Suburban Boomtowns: An Interdisciplinary Mixed-Methods Approach to Addressing Infrastructure Needs. NITC-RR-1263. Portland, OR: Transportation Research and Education Center (TREC), 2020. 
TABLE OF CONTENTS

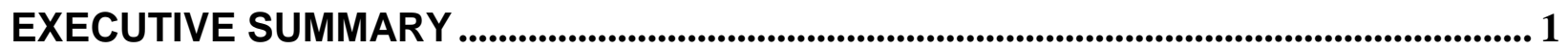

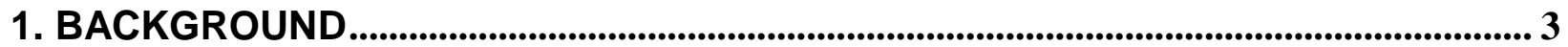

1.1 ECONOMIC GROWTH IN COLLIN COUNTY …….................................................. 3

1.2 TRANSPORTATION IN COLLIN COUNTY ........................................................... 4

1.2.1 Collin County Mobility Plan .................................................................................. 4

1.2.2 Transportation Network System in Collin County ............................................ 7

1.2.3 Public Transit in Collin County .............................................................................. 8

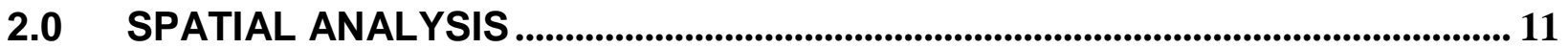

2.1 POPULATION DENSITY OVER TIME WITH TOLL ROAD EXPANSION............. 13

2.2 EMPLOYMENT DENSITY OVER TIME WITH TOLL ROAD EXPANSION .......... 14

2.3 MEDIAN INCOME DISTRIBUTION OVER TIME WITH TOLL ROAD EXPANSION

2.4 BELOW POVERTY DISTRIBUTION OVER TIME WITH TOLL ROAD

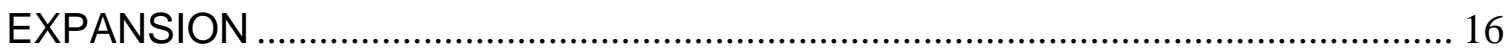

2.5 MINORITY POPULATION DISTRIBUTION OVER TIME WITH TOLL ROAD

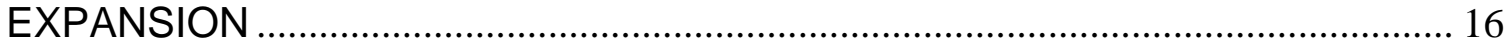

3.0 METHODOLOGY OF MIXED METHODS .......................................................... 18

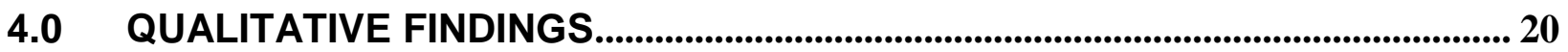

4.1 DEMOGRAPHIC INFORMATION OF FOCUS GROUP PARTICIPANTS ........... 20

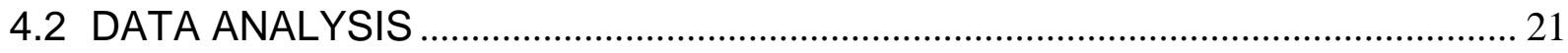

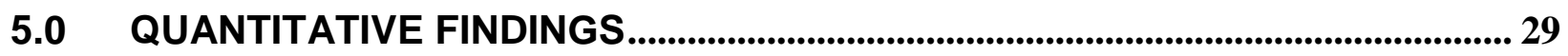

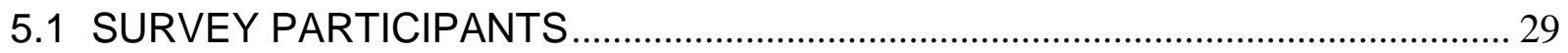

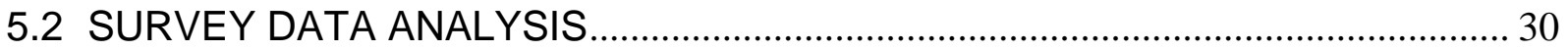

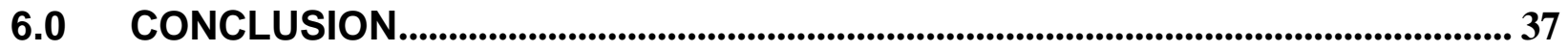

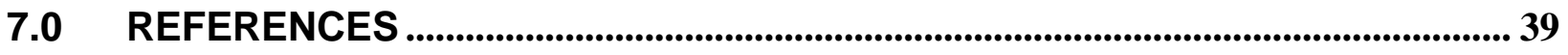

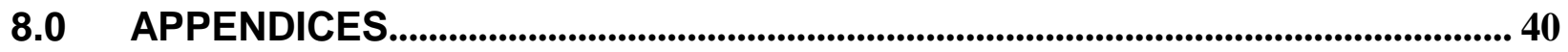

\section{APPENDICES}

APPENDIX A: INSTITUTIONAL REVIEW BOARD APPROVAL $\ldots \ldots \ldots \ldots \ldots \ldots \ldots \ldots . \ldots \ldots$

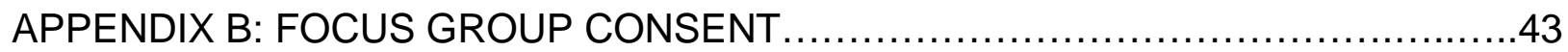

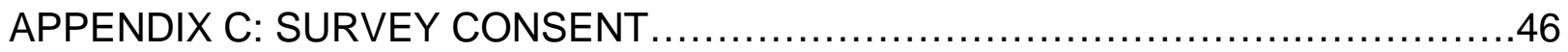

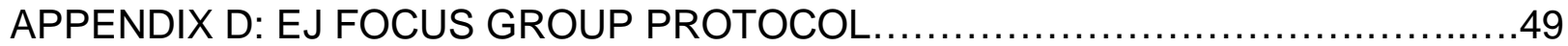

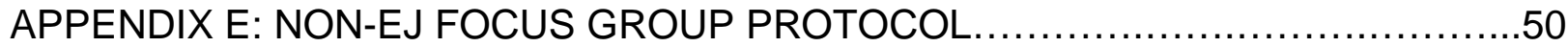

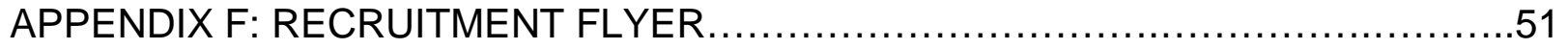

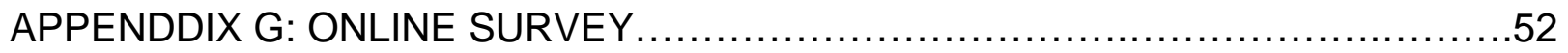




\section{LIST OF TABLES}

Table 1 Focus Group Participants.............................................................................. 20

Table 2 Summary of demographic characteristics of survey responders ....................... 29

Table 3 Different transportation mode users for trips to work .......................................... 32

Table 4 Comparison of transportation mode between EJ and Non-EJ Population ......... 32

Table 5 Preferred vs. typical mode of travel to work for EJ population ........................... 33

Table 6 Preferred vs. typical mode of travel to work for Non-EJ population .................... 33

Table 7 Efficiency of public transit for getting to work according to different mode users

Table 8 Barriers to using public transit for different users .............................................. 34

Table 9 Mode choice vs. purpose of trips ........................................................................ 35

Table 10 Length of residence in Collin County of different transportation mode users for trips to work ............................................................................................................. 36

Table 11 Barriers to using public transit and length of residence in Collin County ......... 36 


\section{LIST OF FIGURES}

Figure 1 Collin County thoroughfare plan ............................................................................ 5

Figure 2 Outer loop in Collin County................................................................................... 7

Figure 3 Major roads network of Collin County (Collin County Engineering Department, 2019) 8

Figure 4 Transit services in Collin County cities ................................................................. 9

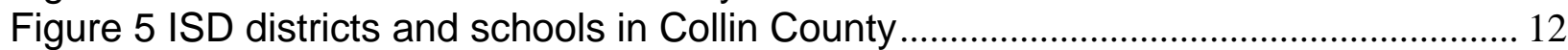

Figure 6 Health Care Assistance in Collin County.............................................................. 13

Figure 7 Population density in Collin County with toll road expansion over time ............. 14

Figure 8 Job density in Collin County with toll road expansion over time .......................... 15

Figure 9 Median household income in Collin County with toll road expansion over time

Figure 10 Percentage of low-income population in Collin County with toll road expansion

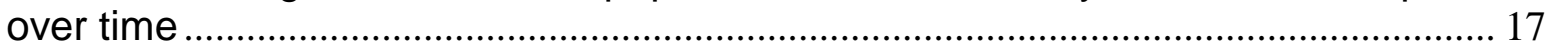

Figure 11 Percentage of minorities in Collin County with toll road expansion over time 17

Figure 12 Transportation Mode Choice and use frequency ................................................. 31 


\section{EXECUTIVE SUMMARY}

The goal of this study was to measure the impact of substantial economic growth in Collin County Texas, a suburb of Dallas that has experiences great economic growth. The research team employed a cross-sectional mixed-methods exploratory design including qualitative and quantitative methods. The research team identified patterns of infrastructure development and their impact on quality of life outcomes for residents, including housing, employment, healthcare, education, and social exclusion, with a particular emphasis on differences between environmental justice (EJ) and non-EJ populations. The team employed a sequential, cross-sectional mixed methods design (Creswell, Klassen, Plano Clark, \& Smith, 2011) to triangulate resident perceptions with survey and spatial data. The study focused on perspectives and data subsequent to 2010, a period of rapid economic growth.

The research team first employed GIS mapping of transportation infrastructure and census (i.e., socio-demographic) profiles at the block group level to show spatial distributions of mobility options in EJ neighborhoods. Results indicated that as transportation infrastructure in the form of tollway roads increased, so did population density, job density, and percentage of minority population. These came with a corresponding decrease in poverty level.

A total of 28 people participated in the focus group portion of this study across four focus groups. Participants were classified as EJ groups or non-EJ groups. The research team asked participants questions from a semi structured protocol to collective qualitative information to address the extent to which transportation infrastructure has maintained pace with corresponding economic growth; how this pace has influenced residents' access to housing, employment, healthcare, education, and social activities. Additionally, this analysis sought to identify any differences between the EJ and non-EJ populations.

Main ideas and themes that emerged from the qualitative focus groups include cost, location of public transit stops, and frequency of stops are the biggest barriers to accessing public transportation within Collin County. The gaps between the environmental justice population and the non-environmental justice populations were clear in the results, that many environmental justice residents had to forego doctor's appointments, employment, and education access due to lack of transportation infrastructure.

In addition to targeted focus groups the researchers developed and disseminated a survey to gather broader data compared to the idiosyncratic focus group data. Specifically, the survey data enabled the research team to codify residents' perspectives into numeric patterns that can be further analyzed to illustrate general patterns. The team collected responses from 200 participants (105 from EJ population members and 100 from non-EJ population members). A power analysis conducted using G*Power (Mayr, Erdfelder, Buchner, \& Faul, 2007) indicates that a sample size of 
200 is sufficient to test an F-test with fixed effects, main effects, and interactions with two groups and an alpha of .05, a small effect size, and a power of .80 (Cohen, 1992).

The EJ surveys were collected in person; the non-EJ surveys were partially collected in person and partially administered electronically. Among the non-EJ populations, webbased surveys offer several advantages in terms of cost and time efficiency (Van Horn, Green, \& Martinussen, 2009). A total of 205 participants completed the survey.

Results indicated similar perspectives and experiences as discovered in focus groups. The majority of participants believed transportation options (shared-ride service, public transit, and walking or riding) are inconvenient. Many residents would like to use public transit if these barriers were not present.

There are several quality outcomes of this study. First, the mixed method approach allowed for triangulation of findings to not only see the numerical data but the depth of the lived experiences of residents in this town, further mapped by transit patterns.

1. Quantitative and qualitative identification of gaps between economic development and transportation infrastructure within a suburban boomtown, with emphasis on comparative perspectives between EJ and non-EJ population members.

2. Quantitative and qualitative identification of the impact of transportation infrastructure within the context of a suburban boomtown community on access to housing, employment, healthcare, education, and social inclusion, with emphasis on disproportionate impact on EJ population members.

3. A methodological model for future research testing the unique links among transportation and - housing, employment, healthcare, education, and social inclusion - within the built environment of a suburban boomtown.

4. Analysis of how transit access correlates with socioeconomic patterns to test the statistical associations among transportation service, perceptions towards service, and socioeconomic profiles of EJ and non-EJ populations 


\section{BACKGROUND}

\subsection{ECONOMIC GROWTH IN COLLIN COUNTY}

Boomtowns" are communities that experience rapid economic and attendant population growth, often due to natural resources extraction (Brown, Geersen, \& Krannich, 1989). Boomtowns frequently celebrate this growth as it brings increased resources and revenue, but this growth is not always met with similarly expanding infrastructures (Morrison, Wilson, \& Bell, 2012). Moreover, extant research has overlooked the impact of this rapid economic growth on boomtown residents (Murphy, Brannstromm, Fry, \& Ewers, 2018). Furthermore, the extant empirical research tends to focus on isolated boomtowns in largely rural communities, e.g., North Dakota, rather than suburban boomtowns, which are increasingly common around urban cores such as Atlanta, Houston, Seattle, and Los Angeles. Most importantly to this project, scant research has considered transportation infrastructure development within the context of suburban boomtowns, specifically transportation needs among individuals already at elevated risks for transportation disadvantage, e.g., environmental justice (EJ) populations including lower-income persons and those with disabilities (U.S. Department of Transportation, 2012).

Collin County, Texas, represents just such a suburban boomtown - it is the fastest growing county in the state of Texas - in large part due to its very low corporate tax rate. Toyota Corporation re-located its North American headquarters to the county in 2017, and other national corporate headquarters include, Fannie Mae, FedEx, Frito-Lay, Hewlett Packard, and J.P Morgan Chase. The county's unemployment rate is $4.5 \%$, relatively equal to the national average; over $40 \%$ of residents earn $\$ 100,000$ or more. More than three quarters (81.5\%) of employed residents commute to work in a car, truck, or van. The low corporate tax rate means that sources of public infrastructure funding are limited primarily to property taxes.

Still, the economic growth has meant that lower-income individuals have faced rising housing costs, particularly in areas proximal to corporate headquarters, and presumably jobs with higher wages. Collin County lacks a county-wide mass transit system, and city services vary, but are limited to buses and shuttles. Recent transportation projects have favored highway construction over public transit. In general, these developments disadvantage EJ populations. These developments also make Collin County an ideal pilot community in which to explore the issues of transportation infrastructure development within the context of a suburban boomtown. 


\subsection{TRANSPORTATION IN COLLIN COUNTY}

Overall, Collin County lacks a countywide mass transit system, and city services vary, but are limited to buses and shuttles. Recent transportation projects have favored highway construction over public transit.

\subsubsection{Collin County Mobility Plan ${ }^{1}$}

The US census conducted in 2010 showed a 61\% increase in Collin County's population, compared to 2000 Census. This population and employment growth requires more transportation facilities and comprehensive mobility plans to serve the current and new residents of Collin County. During the last few years, various entities such as the Texas Department of Transportation (TxDOT), the North Texas Tollway Authority (NTTA) and the Dallas Area Rapid Transit (DART) have initiated several mobility projects that aim to enhance the transportation efficiency and to accelerate the economic growth of the rising population.

Collin County's Mobility Plan, updated every five years, reviews the changing needs of transportation systems for county residents and businesses. The last update finalized in August 2014 serves as a guide for future investments in transportation facilities and services for transportation decision-making processes in the region. The mobility plan consists of four sequential stages including reviewing the past mobility plan, analyzing the county's current and projected population and employment growth, identifying multimodel transportation improvements for short- and long-term ranges, and determining where to allocate funds. The 2014 Mobility Plan introduces the new Collin County Thoroughfare Plan to outline the future road development and support mobility needs of Collin County residents as shown in Figure 1. Various projects were included in the 2040 Plan ranging from new development of road network/alignments to recommendation of location of transportation facilities.

Several projects have been underway or completed since the last Mobility Plan (2007) as below ${ }^{2}$.

- Collin County Outer Loop

Collin County has developed a major outer-loop thoroughfare since 2002 to serve fast growing population and employment. Collin County officials recently refined the technically and locally preferred alignment and finalized the engineering design of more than 50 miles of regional outer loop, connecting FM6 to Dallas North Tollway as shown in Figure 2.

- North Dallas Tollway Extension

North Texas Tollway Authority (NTTA) initiated an improvement project of the Dallas North Tollway (DNT) from Legacy Drive to Gaylord Parkway including ramp reconfiguration, pavement resurfacing, land addition, and barrier replacement. NTTA also

\footnotetext{
${ }^{1}$ https://www.collincountytx.gov/mobility/Documents/mobility_plan/CCMobilityPlan082014.pdf

${ }^{2}$ https://www.collincountytx.gov/mobility/Pages/default.aspx
} 
developed various future projects for extending the tollway from SH 121 to US 380 and beyond.

- FM 545 Alignment Study

This study investigated the improvement alternatives for the farm-to-market road (FM 545), which connects Melissa north of McKinney to Blue Ridge north of Farmersville. The study included right-of-way, widening, roadside clearance and safety improvement.

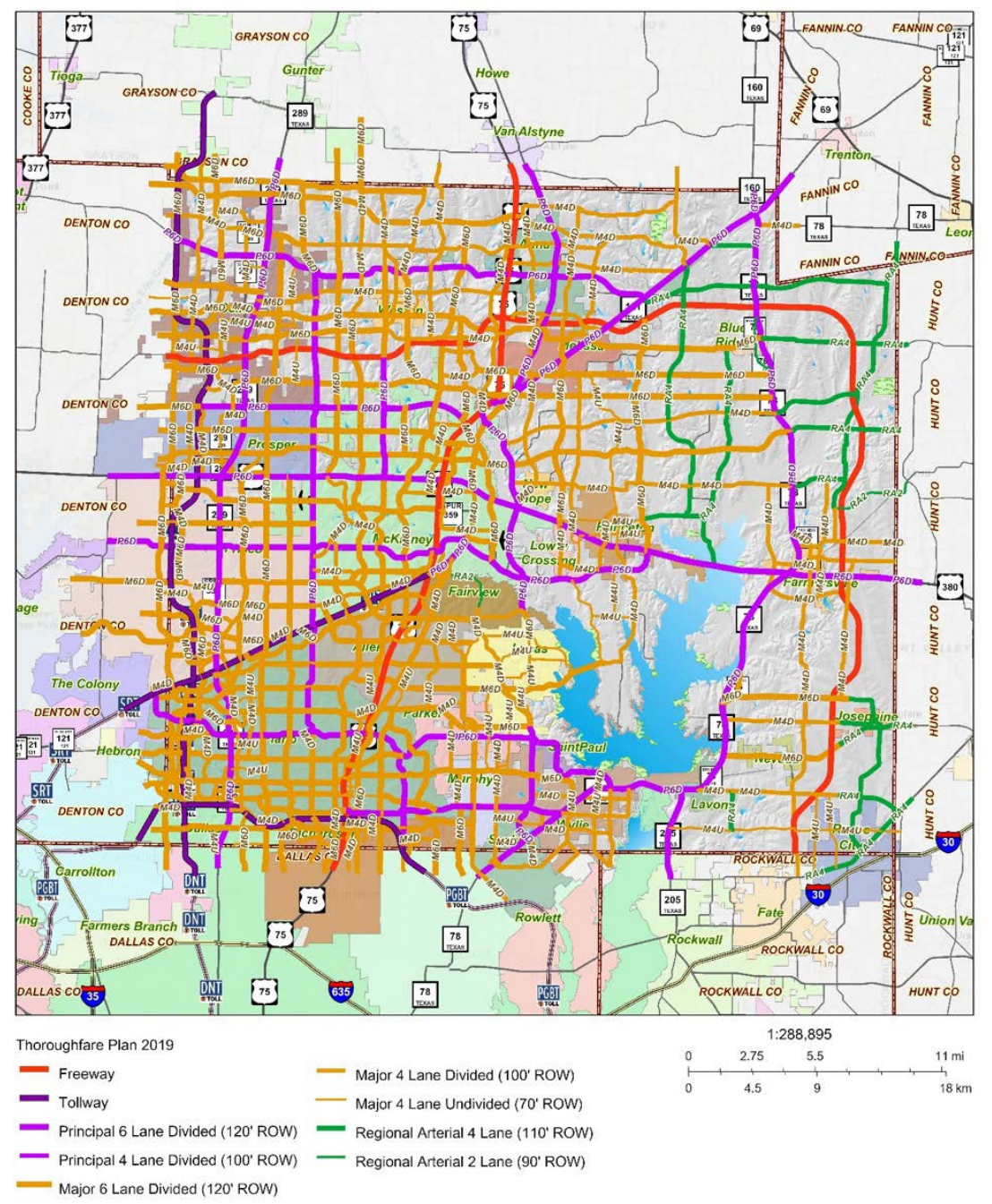

Figure 1 Collin County thoroughfare plan

- County Road Paving Program

Collin County launched a program in 2014 to pave all dirt and rock county roads. Over 400 miles of roads have been paved and widened to enhance safety.

- Northeast Texas Rural Rail District

Collin County has become a member county of the Northeast Texas Rural Rail District (NETEX). NETEX is considering reestablishing the rail that was abandoned and removed in Collin County and parts of Hunt County in the early 1990s. A study is currently being 
conducted by Texas A\&M - Commerce to determine the feasibility of replacing the rail and to evaluate its economic impact to the Northeast Texas region.

- 2007 Transportation Bond Projects

The 2007 bond propositions, developed by citizen committees in Collin County, evaluated and determined the county's viable projects.. The cost of these projects was set to \$235.6 million for 113 transportation projects for the roads within County limits.

- Regional Toll Revenue Projects

The Regional Toll Revenue program expedites transportation projects by providing funds through public- and private partnership financing projects. For example, NTTA used Regional Toll Revenue funds to construct the 26-mile SH 121 toll roads and, in turn, operates and maintains the toll road for 52 years.

- Collin County Intermodal Hub Study

Collin County, NETEX, and the North Central Texas Council of Governments (NCTCOG) examined the feasibility of creating a regional intermodal/logistics hub.. This freight facility may include railroad terminal, distribution facilities, office/retail land development, and potentially cargo airport. The feasibility test recommended the Farmersville site at the intersection of the proposed Regional Outer Loop and the KCS rail line to locate the intermodal hub. 


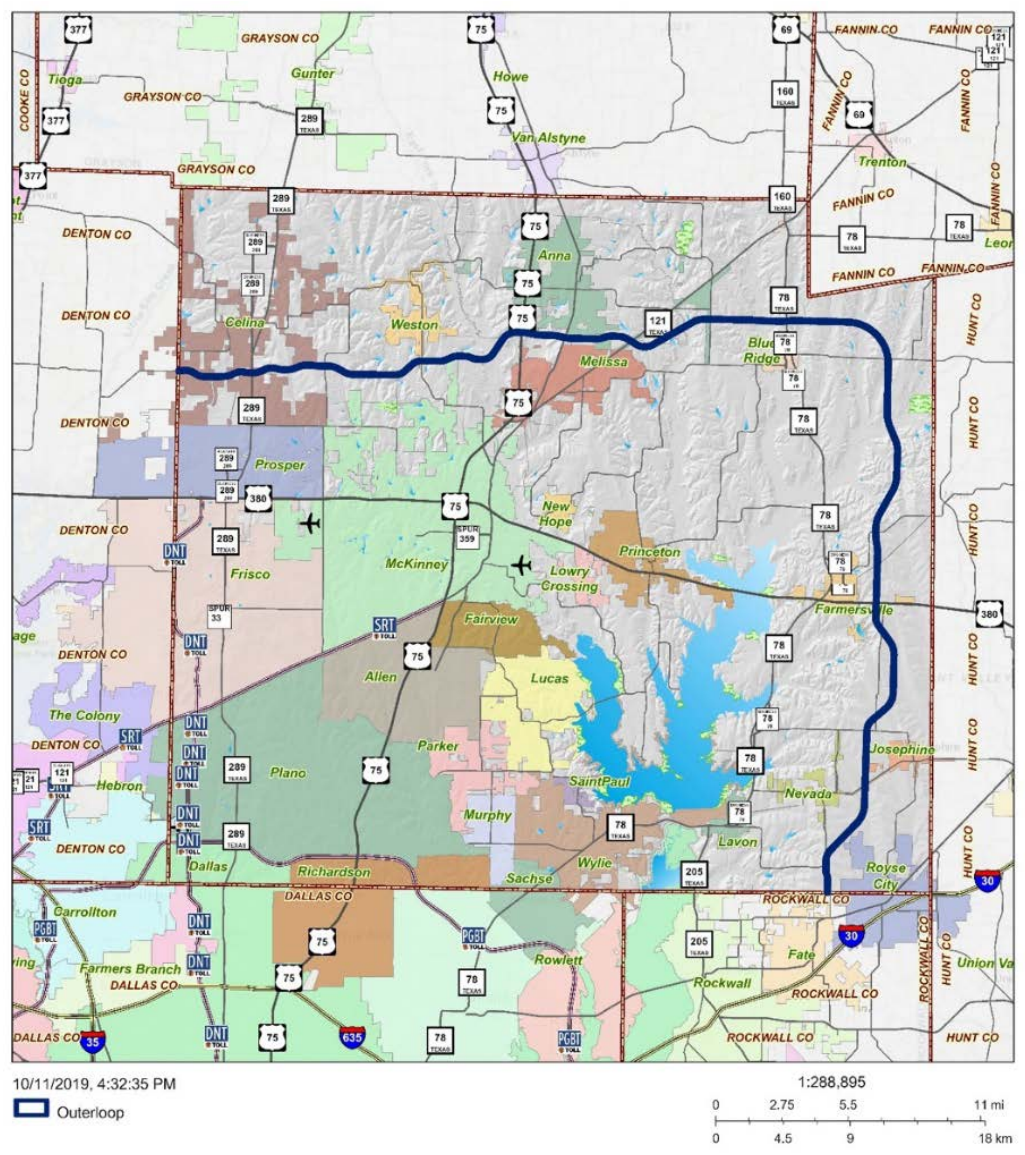

Figure 2 Outer loop in Collin County

\subsubsection{Transportation Network System in Collin County}

The major US and State highways of Collin County include US 75, SH 289, and SH 380, which pass through the cities of Plano, McKinney, Princeton, Allen and Farmersville as depicted in Figure 3 . The busiest sections of these highways show the vehicle miles travelled (VMT) of 12,045,027, 2,671,401 and 2,105,580 vehicle miles per day, respectively. Toll roads passing though Collin County include the Dallas North Tollway (DNT), President George Bush Turnpike (PGBT), Sam Rayburn Tollway (SRT) and Addison Airport Toll Tunnel. The DNT is a 32-mile, six-lane expressway running from Interstate 35E near downtown Dallas U.S. Highway 380, in Frisco. The DNT passes through the multiple cities such as Dallas, Highland Park, University Park, Addison, Farmers Branch, Plano and Frisco. The road opens its first section in 1968 and is still expanding to add 17.6 miles from US 380 to nearly five miles north of the Collin/Grayson county line. The President George Bush Turnpike (PGBT) is a 52-mile, six-lane expressway that provides additional access to U.S. 75, the Dallas North Tollway, Interstate 35E and I-635 by forming a partial loop around Dallas. The PGBT passes through three counties - Dallas, Collin and Denton County - and nine Dallas suburbs cities including Rowlett, Sachse, Garland, Richardson, Plano, Carrollton, Farmers Branch, Irving and Grand Prairie. Since the first segment of the tollway was opened in 
1998, a widening project has implemented from Interstate 20 to State Highway 183 and from north of Belt Line Road (Irving) to SH 78. The Sam Rayburn Tollway (SRT), opened 2008, extended 26.2 miles from the northeast of Business 121 near the Dallas/Denton county line to U.S. 75 in Collin County with six main lanes.

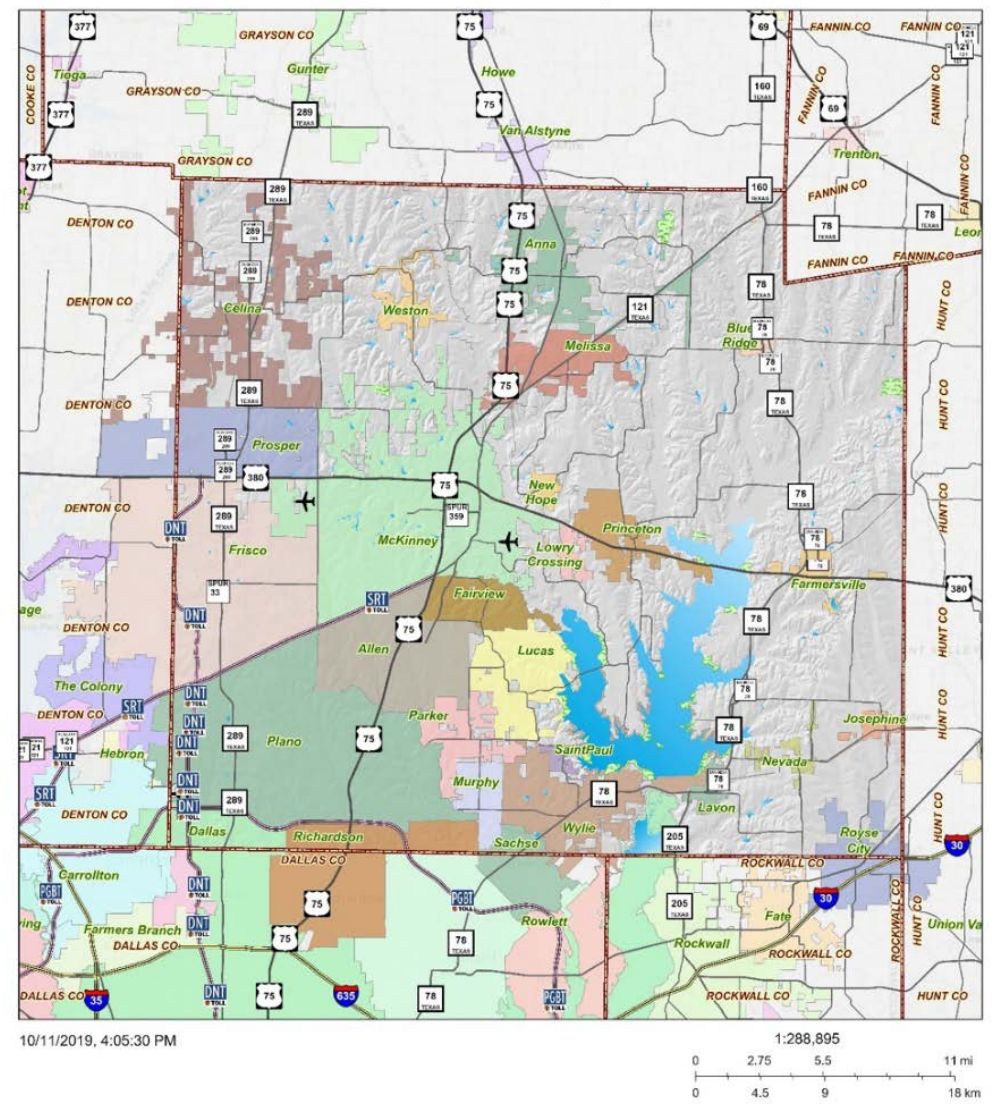

Figure 3 Major roads network of Collin County (Collin County Engineering Department,

1.2.3 Public Transit in Collin County 2019)

\section{DART}

DART is a public transportation serving Dallas and surrounding cities including Plano, and Richardson in Collin County. DART includes buses, commuter rails, and paratransit services to serve more than 220,000 individuals over their 700-square-mile service area. The DART light rail system comprises 93 miles with four lines - the Red Line, the Blue Line, the Orange Line and the Green Line. All DART's trains feature level boarding (especially convenient for strollers and wheelchairs) and higher passenger capacity. The red line, opened in 1996 and completed in its current state in 2002 particularly serves Collin County. Figure 4 showed the map of the cities within DART operating boundaries, local transit system in Collin County, and surrounding areas.

DART also offers curb-to-curb shared-ride service, called DART Rides or Collin County Rides for residents who are age 65 or over or have a disability. DART Rides operates in 
the cities of Plano and Carrollton, and Collin County Rides provides service to Wylie, Allen, and Fairview.

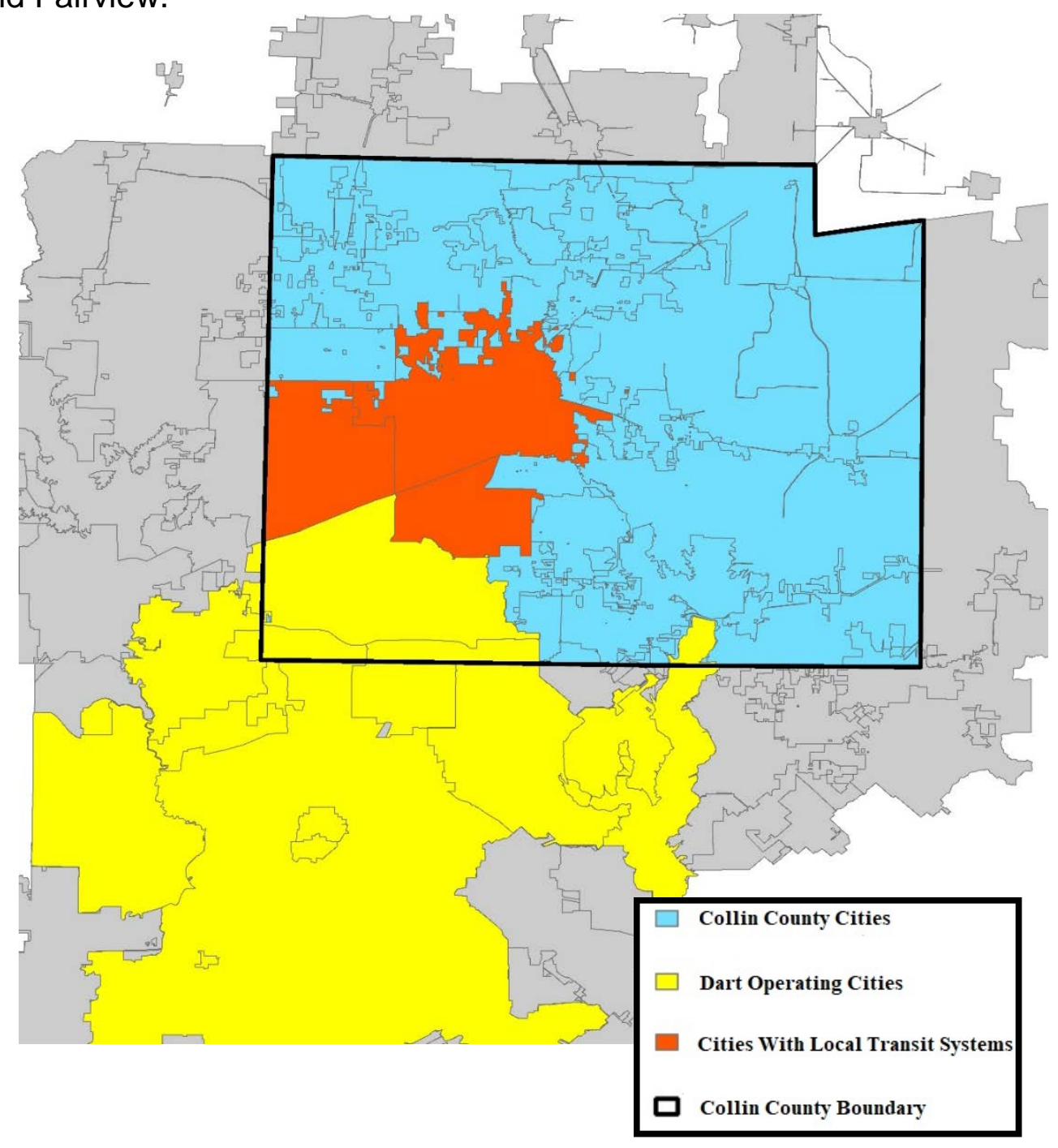

Figure 4 Transit services in Collin County cities

City-Based Transit/Mobility System in Collin County

Among 25 cities partially or entirely located within the Collin County boundary, only four cities, (McKinney, Allen, Frisco and Plano) provide the city or community-based transportation system including curb-to-curb paratransit, fixed route bus or rail services (Refer back to Figure 4).

\section{McKinney}

The City of McKinney, the McKinney Urban Transit District (MUTD) and the Denton County Transportation Authority (DCTA) jointly provide a subsidized taxi voucher program for the older population, persons with a disability, and the lower income population who lives in Celina, Lowry Crossing, McKinney, Melissa, Princeton or Prosper. 
The program matches the taxi service out-of-pocket cost to three-to-one. If a participant spends $\$ 1$ on taxi service, the program matches $\$ 5$; therefore, the participant uses a total of $\$ 6$ for trips within Collin County. This service operates Monday through Friday from 6 a.m. to 6 p.m. and Saturdays 8 a.m. to 6 p.m., with $\$ 2.25$ boarding fare plus $\$ 1.80$ per mile. The service charges a traffic delay time/waiting-time cost of $\$ 0.45$ per every 1.5 minutes.

Since McKinney closed the public transit service after financial troubles caused Texoma Area Paratransit System (TAPS) in 2015, the city is pursuing a designation as an Urban Transit District to directly receive state and federal funds to re-establish public transit systems for residents.

\begin{abstract}
Allen
The City of Allen collaborates with DART to provide additional transportation options for seniors and persons with a disability. The partnership, called Collin County Rides, provides a taxi voucher for senior citizens age 65 and older and/or persons with disabilities who live in Wylie, Allen and Fairview. Any eligible residents receive a taxi debit card from DART to pay for taxi trips anywhere in Collin County for any trip purpose including the trip connecting to a DART station. However, participants must schedule their trip up to two service days in advance (same-day scheduling of trips is not permitted). The service is available seven days a week from 5 a.m. to 8 p.m.
\end{abstract}

\title{
Frisco
}

Denton County Transportation Authority (DCTA) has offered a curb-to-curb demandresponse service for Frisco, McKinney, and Allen since 2015. The residents of Frisco who are age 65 or order or disabled are eligible to use the service if they need transportation for medical-care related purposes. DCTA services are available during the weekdays from 6 am to $6 \mathrm{pm}$. To schedule a trip, passengers need to call the DCTA call center and request their trip 24 hours in advance. The cost of a one-way local trip is $\$ 2$ within Frisco and $\$ 3$ for outside Frisco.

\section{Plano}

In 2002, DART opened two light rail stations in Plano at 15th Street and Parker Road. The light rails connect Plano to other suburban cities such as Richardson, Garland, Carrollton, and Farmers Branch. There are also two bus transit centers in Plano located on the east and west sides of the city. The west transit center is located at 15th Street and Coit Road, near major employers such as Alcatel-Lucent, Medical Center of Plano and Dallas Morning News. The east transit center is near US 75 and Archerwood Street, in proximity to light rail, government and county offices, office complexes and shopping districts. Northwest Plano Park \& Ride facility serves commuters from West Plano to a direct link to downtown Dallas. 


\subsection{SPATIAL ANALYSIS}

Collin County, Texas, represents a suburban boomtown as the fastest growing county in the state, due in part to its very low corporate tax rate. The low corporate tax rate however indicates that sources of public infrastructure funding could be limited to property taxes. Toyota Corporation re-located its North American headquarters to the county in 2017, and other national corporate headquarters including Fannie Mae, FedEx, Frito-Lay, Hewlett Packard, and J.P Morgan Chase recently moved into the region. The county's unemployment rate is $4.5 \%$, which is similar to the national average; and over $40 \%$ of residents earn $\$ 100,000$ or more. More than three quarters $(81.5 \%)$ of employed residents commute to work using their personal vehicles such as a car, truck, or van.

The research team employed GIS to map the transportation infrastructure in Collin County and Census (i.e., socio-demographic) data in block group level to show the spatial distributions of population growth and mobility options in Collin County. The team compared the spatial distributions from 1990 to 2017 to understand how toll expansions and new transportation facilities has affected the residence location and employment distribution. The team also showed the median income and poverty distribution over time to understand how environmental justice populations have relocated in Collin County to cope with increasing rent and toll-road-oriented transportation network developments. The team used the TxDOT roadway and NTTA database to collect road data including toll road locations.

The first set of Figures showed the locations of school and health care centers in Collin County. Figure 5 showed 21 ISD boundaries and schools in the region. Among these 21 ISDs, Allen, McKinney, Frisco and Plano have showing fastest growing student numbers schools over the last several years. 


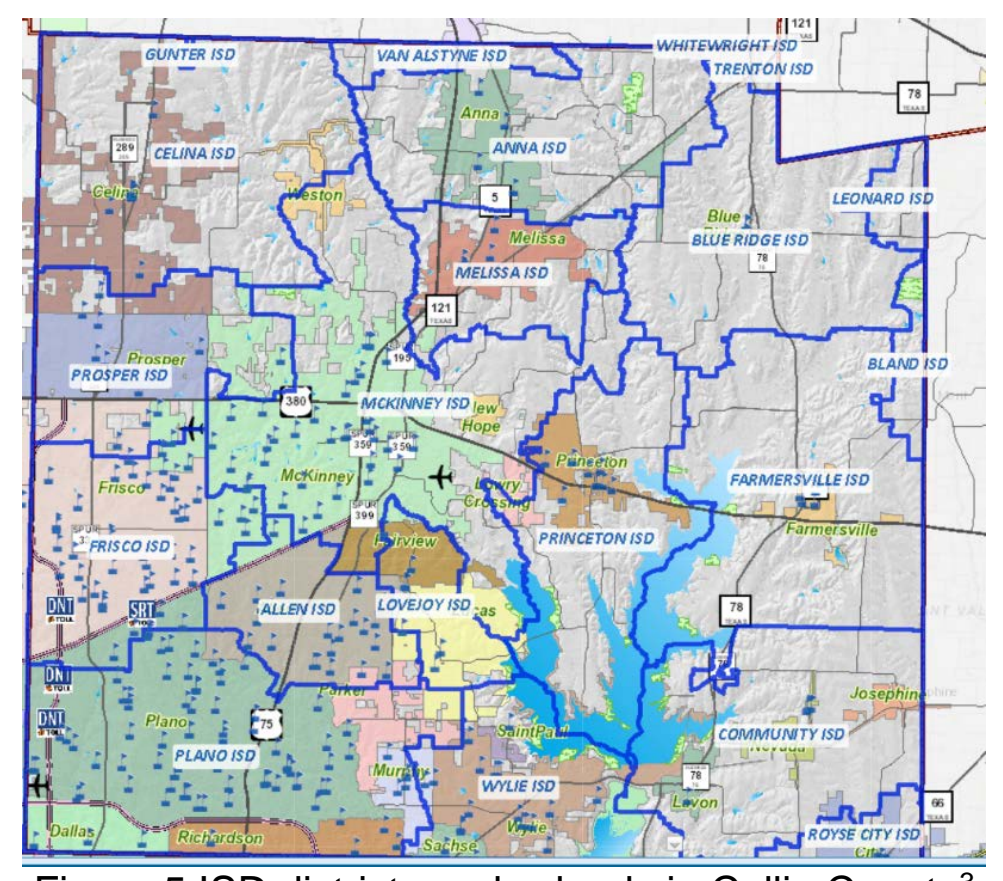

Figure 5 ISD districts and schools in Collin County ${ }^{3}$

A partnership between Collin County's Health Care Services and Prima Care Medical Centers provides primary care services for lower income families who earn less than $100 \%$ of the federal poverty threshold and who are in need of urgent care services. The patient will pay $\$ 20.00$ co-pay and the County provides the rest of the cost from the visit. Collin County also provides funds to non-profit organization and health clinics that offer additional health care assistance for uninsured residents, lower income families, homeless individuals and those affected by domestic violence. Figure 6 showed the location of primary care and other seven additional health care centers that provide prescription assistance, medical care, and emergency shelters.

${ }^{3}$ https://gis.collincountytx.gov/ 


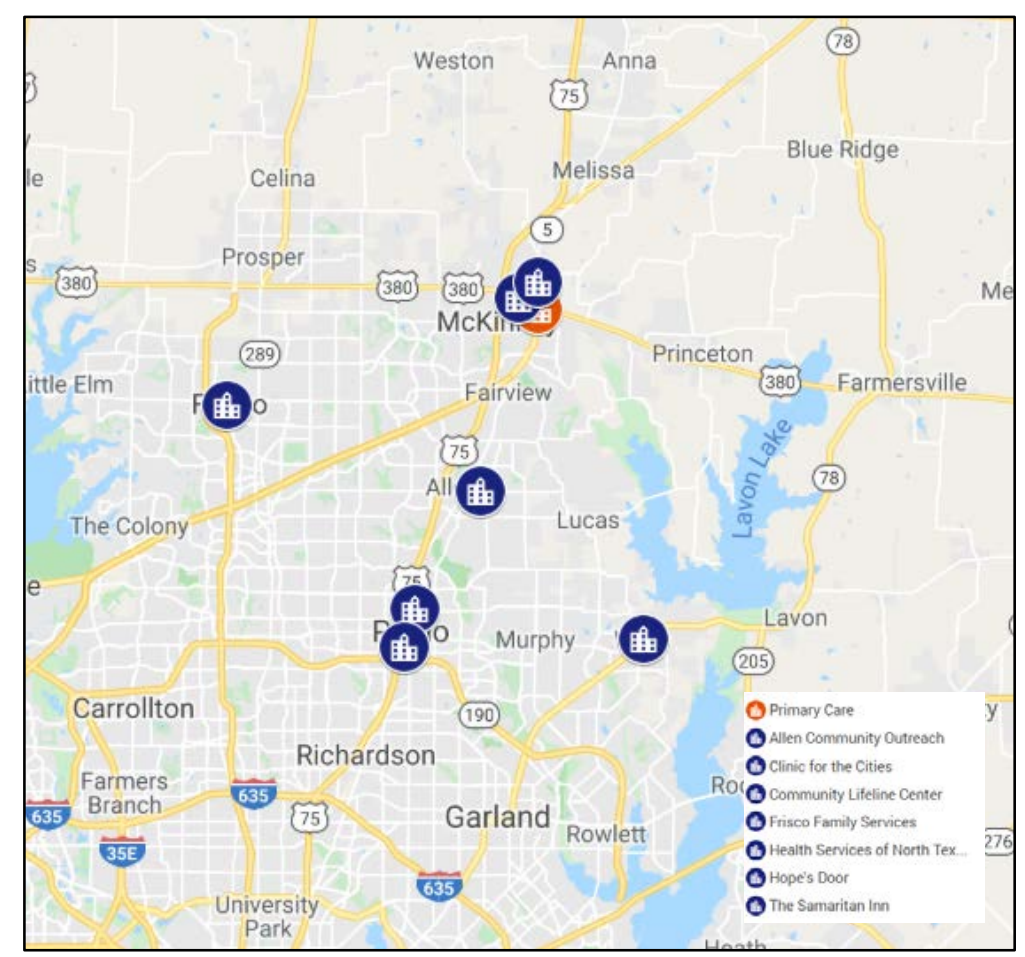

Figure 6 Health Care Assistance in Collin County

\subsection{POPULATION DENSITY OVER TIME WITH TOLL ROAD EXPANSION}

The first analysis looked into the population density from 1990 to 2017 with the toll road expansion as shown in Figure 7. The population density in this study refers to the number of people per acre on unprotected land. The density was higher in southwest and central areas of Collin County in 1990, and continued to increase for the next 40 years, particularly along the toll roads. On the other hand, the rest of areas (beyond the southwest part of the county) maintained almost similar population density (less than three persons per acre) in the last three decades. 


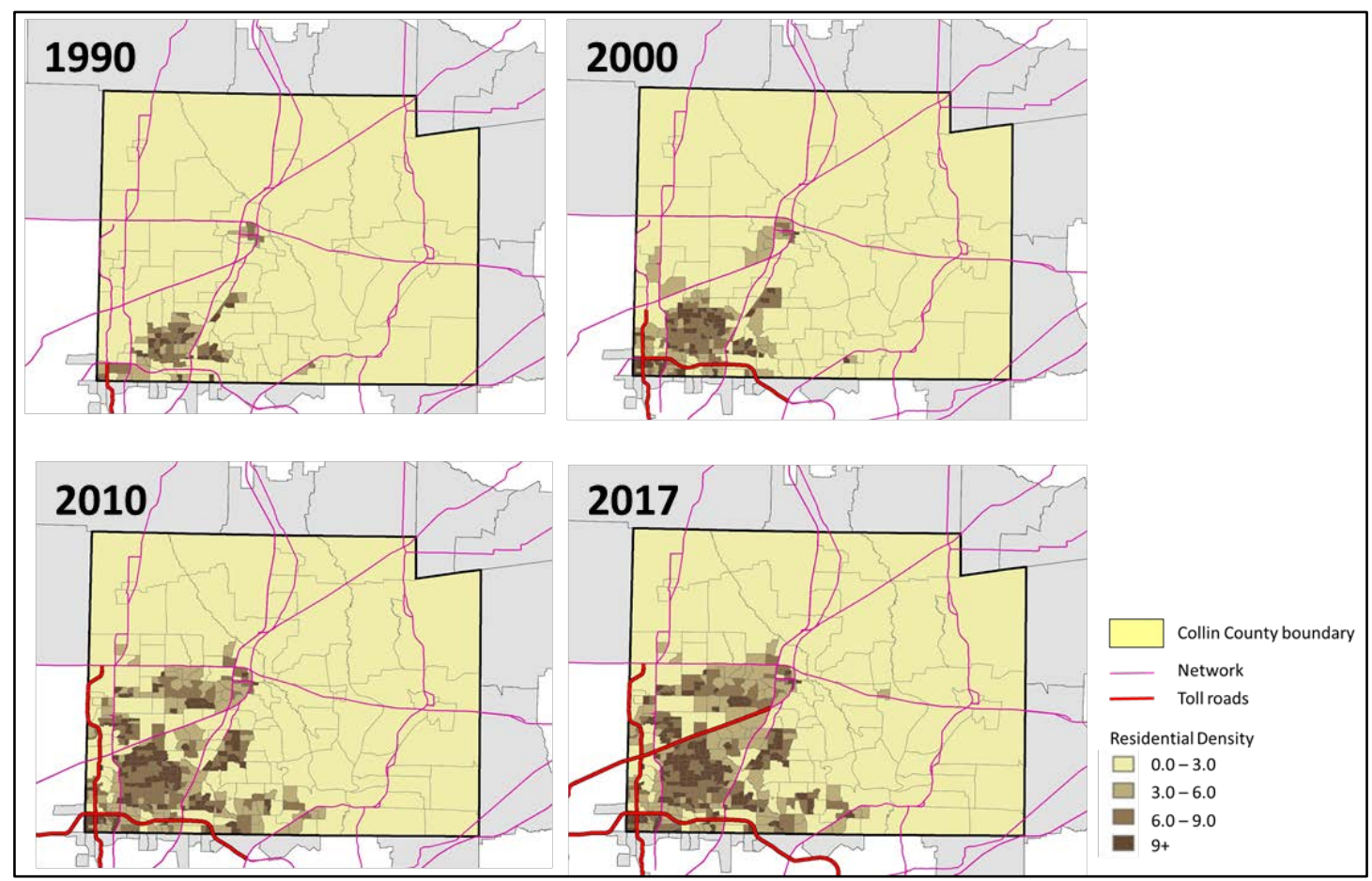

Figure 7 Population density in Collin County with toll road expansion over time

\subsection{EMPLOYMENT DENSITY OVER TIME WITH TOLL ROAD EXPANSION}

The research team used the job density (i.e., the ratio of the number of jobs per acre on unprotected land) to show the spatial distribution of employment in Collin County over time. The resulting job density maps (Figure 8) showed that jobs have increased over time in Collin County focused on the southwest of the region. The maps also clearly showed that the job density is highest along the toll roads in all years.

\subsection{MEDIAN INCOME DISTRIBUTION OVER TIME WITH TOLL ROAD EXPANSION}

Figure 9 shows the maps of median household income in Collin County. Overall, median household income has increased in Collin County since 1990. In 1990, most of BGs except the southwest part of the county showed the relatively similar income levels of less than $\$ 50,000$. Between 2000 and 2010, the BGs located along SRT line showed noticeable income growth, and most of western County showed higher income in 2017. In 2017, more than $50 \%$ of BGs showed more than $\$ 100,000$ household income, with an average of $\$ 94,933$ for the entire county. The eastern part of the county showed generally lower income distribution mostly between $\$ 50,000$ and $\$ 100,000$. 


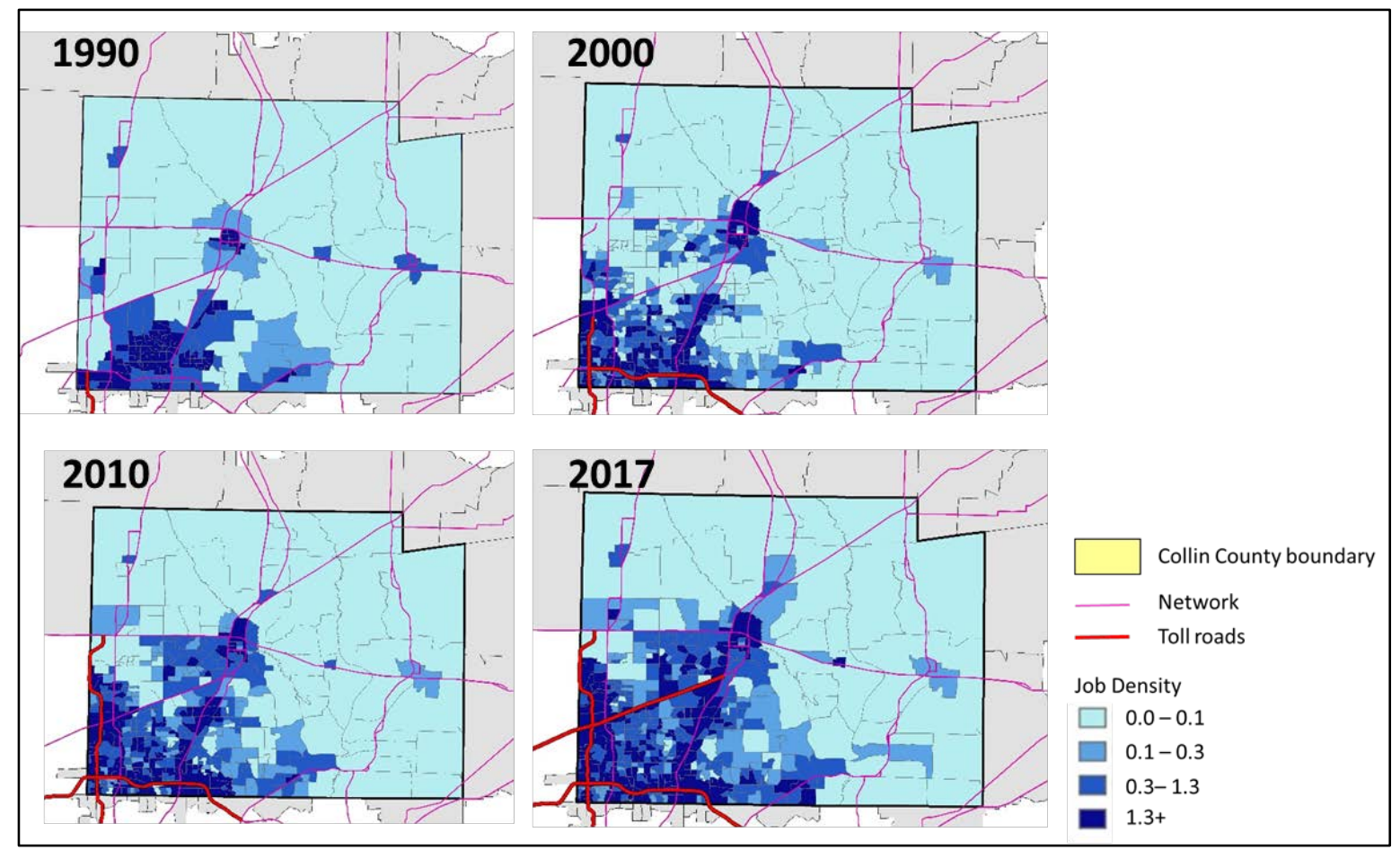

Figure 8 Job density in Collin County with toll road expansion over time

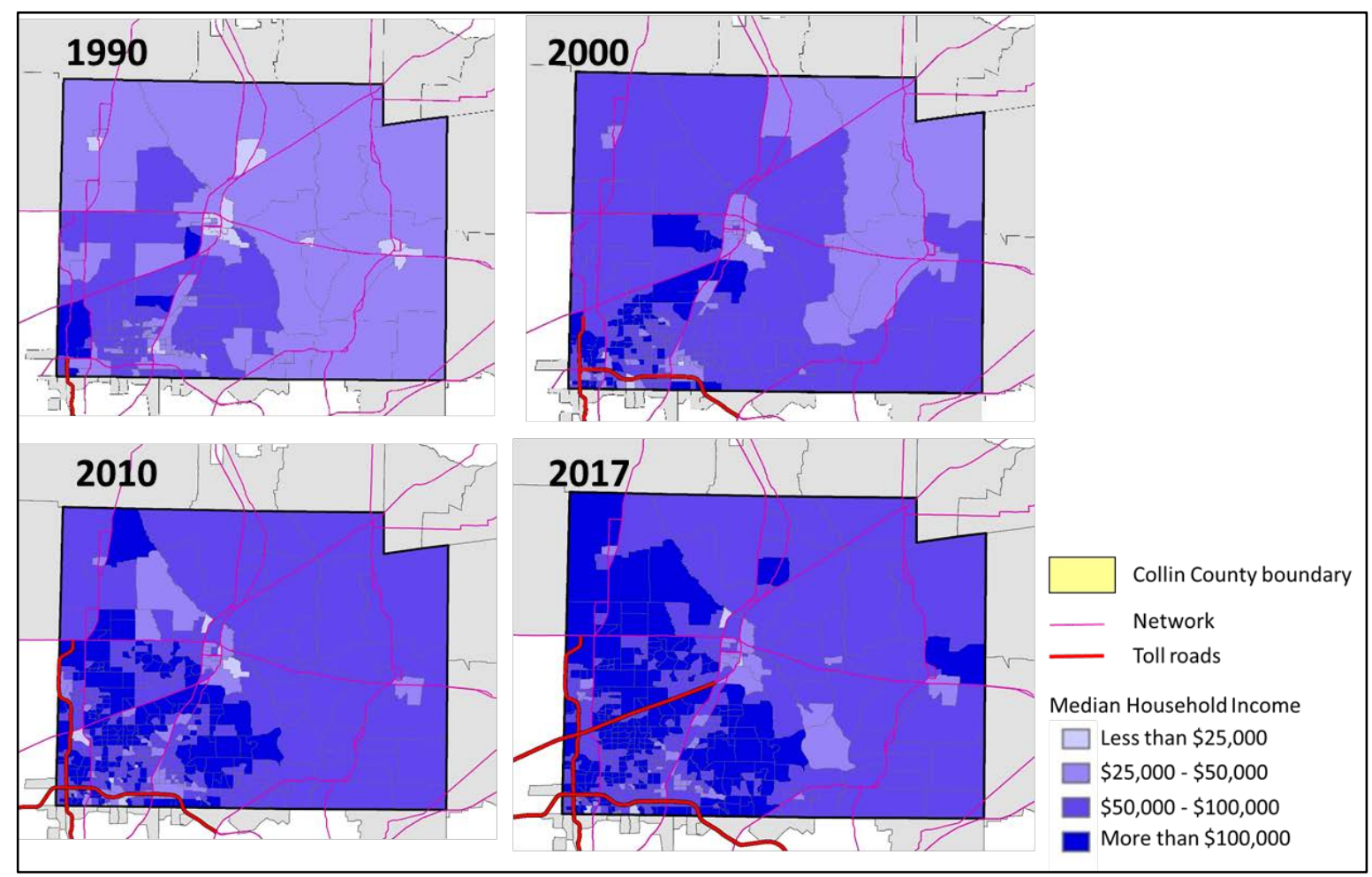

Figure 9 Median household income in Collin County with toll road expansion over time 


\subsection{BELOW POVERTY DISTRIBUTION OVER TIME WITH TOLL ROAD EXPANSION}

Figure 10 compared the spatial distribution of poverty level into four categories: BGs with less than $5 \%$ household below poverty level, $5-10 \%, 10-25 \%$, and over $25 \%$. The poverty level is defined by US Census Bureau to specify dollar amounts considered the minimum level of resource to meet the basic needs of a family. Thresholds vary by the number and the structure of the family. In 2017, 6.9 percent of individuals in Collin County are below poverty level. Figure 8 showed that the higher poverty BGs were concentrated in the central region in 1990 and 2000, and expanded to the western part of the County along the DNT, however in 2017, only two BGs in the central County showed more than $25 \%$ of poverty level. Compared to 1990 where very few BGs showed over $5 \%$ of poverty in the southwest corner of the County, more BGs showed higher poverty levels along the toll roads of DNT and PGBT in 2010. The number of BGs of more than $25 \%$ poverty level in 2017 were significantly decreased in the overall region and BGs between $10 \%$ to $25 \%$ were concentrated along the PGBT.

\subsection{MINORITY POPULATION DISTRIBUTION OVER TIME WITH TOLL ROAD EXPANSION}

Figure 11 showed the percentage of minority population (i.e., all but non-Hispanic white population). In 1990, Non-Hispanic White Population was the dominating population throughout the County; however other demographic populations (defined minority population in this study) has increased particularly in the southwestern part of the County where new employment and new toll road has been expanding since 2000 . 


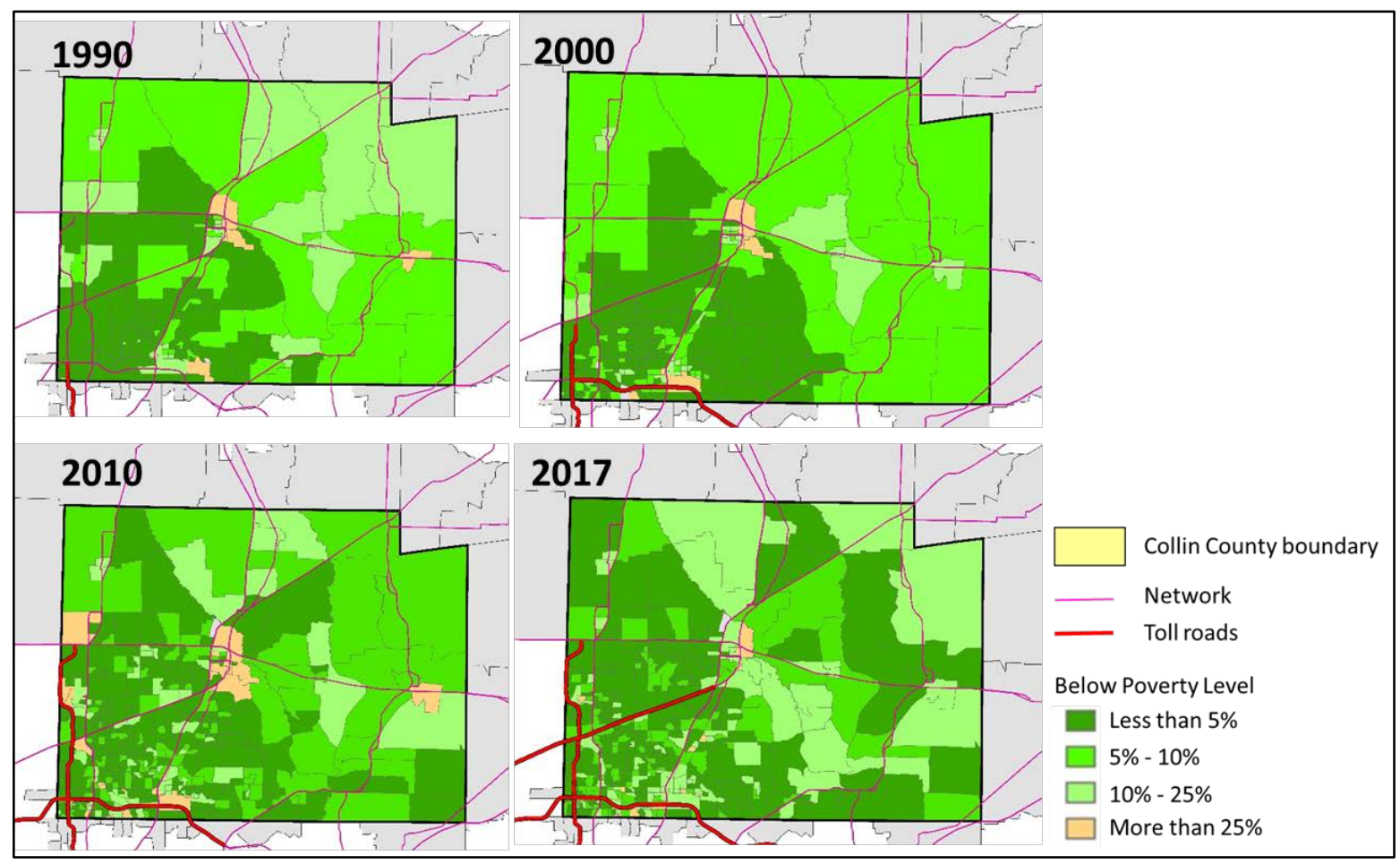

Figure 10 Percentage of low-income population in Collin County with toll road expansion over time

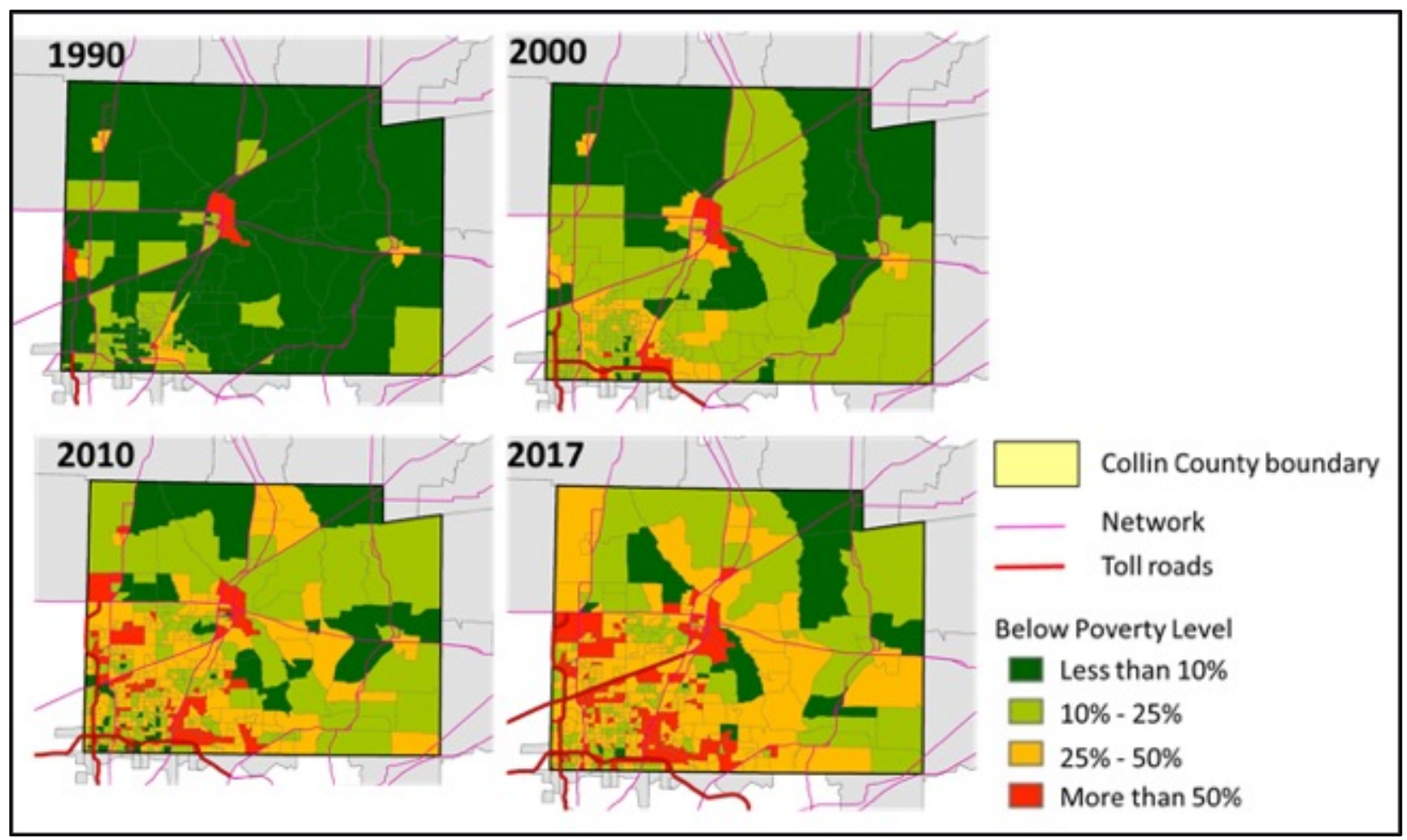

Figure 11 Percentage of minorities in Collin County with toll road expansion over time 


\subsection{METHODOLOGY OF MIXED METHODS}

This study sought to provide a multidimensional model of transportation access, usage, and perspectives in a suburban boomtown. This study used focus groups and an online survey to gather data from Collin County residents. Before conducting any of the data collection, the research team secured UTA Institutional Review Board (IRB) approval for human subjects' projects. This study utilized a mixed-method, sequential exploratory design that employed an initial phase of qualitative (focus group) data collection and analysis followed by a phase of quantitative data analysis.

The two phase design included: 1) focus group to identify common things among environmental justice populations and non-environmental justice populations and 2) were triangulated by the subsequent quantitative online survey. The four focus groups generated in depth response to the previously mentioned research questions. The focus groups utilized open-ended and semi-structured protocol questions in order to draw rich explanations, descriptions, and examples from participants in the study.

Recruitment of focus group participants was twofold. The recruitment of EJ participants took place in cooperation with local human service agencies in Collin County including food banks, shelters, youth organizations, churches, and the homeless coalition. Interested participants were to contact the point person within the agency, who then forwarded contact information to the researcher. The researcher then set up a time to come to the agency and conduct a focus group for participants who had expressed interest. At the beginning of the focus group, researchers read the consent form and for the non-EJ recruitment, an email containing the study recruitment script, IRB approval number, and contact information of the PI was sent to the homeless coalition listserv and other partners of the coalition. Interested participants replied to the researcher, after which they received an email with the link to a brief consent form and demographic questionnaire. Focus group times were then provided to each participant.

EJ participants were given Walmart gift cards for their time, while non-EJ participants were entered into a raffle for an electronic tablet. Each focus group consisted of up to 12 members and lasted between 45 minutes and 1.5 hours. One faculty member on the research team moderated each focus group and the assistant recorded the in person focus group. One online focus group was held with non-EJ participants using Zomm.us a conference platform that allows audio and video recording. Once the focus groups were completed, the audio was transcribed using Rev.com. Thematic analyses were conducted using Dedoose.com qualitative software.

In the second phase of the sequential mixed-method analysis, the researchers administered an online survey to $100 \mathrm{EJ}$ and 100 non-EJ participants using Qualtrics. Questions in this survey were able to further illustrate the data collected in the focus groups. These questions included topics such as frequency and type of transportation 
usage, major concerns about access to transportation, and views on transportation infrastructure. A copy of the survey is attached in the Appendices.

A total of 203 participants completed the survey. For the non-EJ population, participants were recruited at a local homelessness symposium. Non-EJ participants completed the survey on electronic tablets, and the consent for participation was the first question on the survey. For the EJ participants, the researcher partnered with local agencies to collect data on site using an electronic tablet. The researcher first read the consent form to participants and after getting consent, allowed participants to complete the survey online. EJ participants were given a gift card for their participation and non-EJ participants were entered into a raffle for an electronic tablet. 


\subsection{QUALITATIVE FINDINGS}

\subsection{DEMOGRAPHIC INFORMATION OF FOCUS GROUP PARTICIPANTS}

Table 1 Focus Group Participants

\begin{tabular}{ll}
\hline VARIABLES & $\%(\mathrm{n}$ \\
\hline Gender (Non-EJ) & $84.6 \%(11)$ \\
\hline Female & $15.4 \%(2)$ \\
\hline Male & \\
\hline Age (Non-EJ) & $6.7 \%(1)$ \\
\hline 18-24 years old & $6.7 \%(1)$ \\
\hline 25-34 years old & $46.1 \%(6)$ \\
\hline 35-44 years old & $15.3 \%(2)$ \\
\hline $45-54$ years old & $23.1 \%(3)$ \\
\hline $55-64$ years old & $(0)$ \\
\hline 65 or older & \\
\hline Race/Ethnicity (Non-EJ) & $46.1 \%(6)$ \\
\hline Black/African American & $46.1 \%(6)$ \\
\hline Caucasian & $(0)$ \\
\hline Hispanic & $0)$ \\
\hline Asian & $3.3(1)$ \\
\hline Other & \\
\hline Gender (EJ) & \\
\hline Female & $53.3 \%(8)$ \\
\hline Male & $46.6 \%(7)$ \\
\hline Age (EJ) & $80 \%(12)$ \\
\hline 18-24 years old & $(0)$ \\
\hline 25-34 years old & $0(0)$ \\
\hline 35-44 years old & $13.3 \%(2)$ \\
\hline 45-54 years old & $6.6 \%(1)$ \\
\hline $55-64$ years old & $0(0)$ \\
\hline 65 or older & $60 \%(9)$ \\
\hline Race/Ethnicity (EJ) & $20 \%(3)$ \\
\hline Black/African American & $(0)$ \\
\hline Caucasian & $(0)$ \\
\hline Hispanic & $20 \%(3)$ \\
\hline Asian &
\end{tabular}


There was a total of $15 \mathrm{EJ}$ focus group participants $(\mathrm{N}=15)$ of which the majority were female. The EJ population age ranges from 18 and above, but most of them (80\%) were between 18 and 24. EJ participants mainly identified as African American ( $\mathrm{N}=60 \%)$. The non-EJ participants totaled $11(\mathrm{~N}=11)$ and the majority were also female. The age range, like the EJ participants was 18 and above; however, the non-EJ participants were predominantly (46.1\%) aged 35-44. The non-EJ participants identified themselves equally as Caucasian and African American (46.1\%)

\subsection{DATA ANALYSIS}

Qualitative Focus Groups:

In the qualitative portion of this study, four focus groups were conducted with residents of Collin County: two with environmental justice (EJ) and two with nonenvironmental justice (non-EJ) populations. Participants were asked questions to elicit their experiences and perspectives of economic growth and transportation infrastructure in Collin County. Results of the qualitative data analysis highlighted issues in three primary areas: issues with existing public transit systems; issues related to missing transportation infrastructure within communities; and issues faced by individual residents as a result of the current public transit system. Each of these topics more or less overlaps with one of the research questions for this study and will be discussed in more detail below.

\section{Issues with existing public transit systems}

Research Question 1: To what extent has transportation-infrastructure maintained pace with corresponding economic growth, from the perspectives of suburban boomtown residents?

The overwhelming majority of participants in this study acknowledged the great opportunity for Collin County in its booming economy with many larger corporations and businesses bringing not only people but new housing and job opportunities to the area. One focus group participant described the economic growth as "booming - absolutely explosive in the number of corporations that have come into Collin County." This participant noted both the "big major names" and also the smaller, supporting companies that have relocated to North Texas to support these entities. Others shared similar sentiments about the "explosive" growth. The very real signs of an economic boom included an increase in both large and small businesses, hundreds of homes and numerous restaurants and retail shops going up. As the benefits and seeming opportunities have increased, so have the problems of heavier traffic, higher costs of goods and services, increased toll rates, and the growing pains of rapid community development.

While the economic growth in Collin County has been explosive, participants from both EJ populations and non-EJ populations overwhelmingly believed that transportation infrastructure has not kept pace with that growth. One non-EJ participant characterized the infrastructure as "decades behind where they need to be." More than 
one participant characterized their perception that transportation infrastructure was an after-thought for city or community developers. An EJ resident shared this perspective: "The economy has boomed. And unfortunately, it seems that, when that takes place, it's always the big housing developments and all that that happens first, and then all of a sudden they're like, 'Oh, okay, now we gotta expand the roads, and create a tollway, and do this and do that..' It's like they leave the infrastructure for last. Public transportation seems to be one of the last thoughts that's on the list." Another, non-EJ, resident, stated, "I don't even know if it [transportation infrastructure] was even on the decision-making agenda." This has major implications for such a sprawling North Texas county which in many ways may serve as a microcosm of Texas, a known destination for economic opportunity. A non-EJ resident described the gap between growing opportunities and lack of transportation infrastructure, specifically for residents relocating from transportation-supported communities: "Yeah, there is none. In my work, we hear that quite often because Texas is really right now - particularly North Texas is waving the big flag. Everything is here, right? Opportunities are here...So we have to break the bad news to them that, that public transportation is not available. And we've even had people come, [who] didn't have [a] license because they were coming depending on a public transportation system."

A common consensus was that Plano is the only major city in Collin County with a solid transportation infrastructure. McKinney was most often cited as not having any public transit, but other larger cities such as Frisco and Allen were also regarded as not having public transportation resources. Given the infrastructure gaps in these more established cities, presumably even greater challenges exist for EJ residents of the more rural communities of Collin County who rely on these larger cities for access to their needs. Residents frequently noted that the DART train only goes as far north as the Parker Road Station in Plano - and expressed the desire for the train to connect residents living further north in the county with a single, direct mode of transportation throughout. One non-EJ resident stated, "The DART stops in Plano, the DART train. And so, anybody who wants to get to McKinney or Frisco or anywhere, you can't take public transportation to any of these other cities." More than one resident discussed wanting to have a single system with the ability to pay once and traverse between destinations in Collin, Dallas and Tarrant Counties.

Despite Plano having the best available public transit system in Collin County, residents noted the existing system is not without inadequacies. Participants noted infrequency of routes, portions of the city without bus saturation (e.g. West Plano), cost, and lack of clearly defined bus stops as issues. Due to these issues, many residents who rely on public transit reported either being forced to spend considerable time getting to a destination, having to walk long distances even after riding a bus, or having to pay a premium for Lyft/Uber to get somewhere in a more direct route. Some residents also mentioned safety concerns about utilizing the current transportation system, and one noted the possibility of racial disparities in which stops DART train attendants chose to check passenger tickets.

Issues related to missing transportation infrastructure within communities 
Research Question 2: How has this pace influenced residents' access to housing, employment, healthcare, education, and social activities?

In any community, residents' access to housing, employment, healthcare, education and social activities are linked to the vibrancy of that community. Optimally, those who reside and work in a given community would have equal access to resources and services in that community. The present study sought to understand residents' perspectives of these components of life in Collin County. Responses from EJ and nonEJ focus group participants alike illuminated gaps in the experience of equal access among different segments of the Collin County population. This poses an important question about whether all residents are able to experience the county's full vibrancy. EJ and non-EJ residents discussed their access to the following points of interest: housing, employment, healthcare, education, and social activities.

\section{Housing}

Overall, Collin County residents acknowledged the housing boom that has coincided with the economic boom, while lamenting the rising costs of housing. This rise in prices has prohibited many residents from being able to afford to live in the bigger cities within Collin County. One non-EJ participant noted, "Because of the boom, the housing market is exploded so you can't afford to live here, although your job's here and so you're being forced to kind of live in these...more remote cities." One respondent noted that previously more rural cities such as McKinney and Anna have been built out to accommodate housing needs. For those who can afford to live closer to the city centers but do not possess personal transportation, their housing choices are severely limited by lack of public transit. Some residents reported having to try to live within walking distance of where they work due to not having bus or train access, while others in the city center reported having to wake up extremely early just to get to the bus stop and start the convoluted journey to work. Another non-EJ resident attributed increasing homelessness to the rising cost of living: "[A] lot of foreign entities are buying up properties here... Matter of fact, everyone that I know is selling houses is pretty much, everyone is foreign and they're buying up really fast and so you're seeing the property value go way up and the homeless population go up right along with [it]."

\section{Employment}

While the employment opportunities in Collin County are plentiful, many workers have a hard time engaging in gainful employment in the new retail and restaurant locations. Both non-EJ and EJ populations reported that local employers are finding it difficult to staff their businesses because of costs of living that exceed earnings from low-wage jobs. In many ways, provision for the needs, including transportation, of the workers that sustain many of these businesses may have been an oversight by community developers. One non-EJ focus group participant stated, "When you build the population, you build retail... and commercial and the people that man those jobs need the transportation. People who own retail and restaurant businesses are unable to staff. Like, it's a big problem because nobody around here - their staff can't afford to live here and if they can't afford to live here, they can't afford to stay. There's no transportation to get here." Similarly, one EJ focus group participant commented, "It kinda depends on 
where Collin County wants to go, because they want employees to manage the restaurants, and the grocery stores, and the Walmart, and all those types of things. They want service workers but there needs to be transportation for somebody who earns that type of salary." Some low-wage earners may be driven out to the more rural, affordable communities by steep housing costs in the larger cities. In these smaller communities, lack of public transportation poses an additional barrier to residents' ability to secure and maintain employment. Some may be forced out of the workforce simply for lack of available transportation to get to work.

Despite additional challenges faced by those residing in more outlying areas of Collin County, even those in one of the largest cities, Plano, face hardships of inadequate public transit. Limited bus routes and stops make it very difficult for people to get to work on time, buses run late or early, and then workers even at a company as large as Toyota may still have to walk a mile to work after they get off the bus. The young adult who reported this experience was physically able to walk the mile, but others may not be able, given age, health conditions or physical limitations. These are tremendous hardships placed on workers who are willing to work, but also must work to get to work - often by spending extra unpaid hours to get to a destination simply because of an inefficient system. One resident spoke to how even her uphill-battle against these hardships still left her vulnerable to consequences with her employer: "The way that I traveled, I still wouldn't get to work on time. Even though I got up as early as I possibly could I was still maybe five minutes or ten minutes late each day.... and that goes into my work where I would get documented behind, then." Still others noted that lack of effective public transit would likely deter some workers from taking time off for appointments, due to fear of losing their jobs.

\section{Healthcare}

Transportation infrastructure literally means life or death to some Collin County residents. With the bus routes that do exist, some people are still late to work or healthcare appointments - or choose not to go - because there is no direct route to their needed destination. In the case of families with children, there is an added scariness of not being able to make it to an Emergency Room in an emergency without incurring the additional cost of an ambulance ride. Most participants said they would not rely on public transportation as it currently exists in Collin County. However, many EJ residents do not have that luxury. Instead, they face the additional burdens posed by not having personal transportation. One young mother stated, "Well, to be honest, as far as doctor's appointments, they [her children] have Medicaid to take them, so they get help with the transportation... But if I didn't have that, then we wouldn't go." Even with the provision of transportation, this mother indicated compounding logistical challenges. Once she was told the transportation would only be provided for the identified child with the appointment, meaning she would need to pay a babysitter to care for her other children. Other times communication and scheduling difficulties with the transporter caused her to miss rides. Additionally, this mother highlighted that her already-limited selection of available Medicaid providers is further limited by her lack of transportation. She stated, "You might say, well I found a good doctor in McKinney, but since I have to take the bus since [sic] the bus doesn't run in McKinney...Good doctors in McKinney, but I can't get there..." Thus, there appear to be challenges not only with whether - and 
at what additional cost - children and families can access the doctor but also with what quality of doctor they are able to access. Lack of transportation directly relates with lack of healthcare access and equity.

\section{Education}

Another impact of lack of transportation is educational opportunity for lower income families. Students who are coded as homeless can access their schools of origin through the McKinney-Vento Homeless Assistance Act. However, the provision of transportation under this act does not minimize the possibility of added hardship for economically disadvantaged children. One professional stated, "I had a parent that was homeless and she did not want to pull her child out of the Plano ISD. And they lived far away. And so that was an issue getting her kids on, on public transportation to get them here because the schools are so, so great." Thus, the experience for the student who has to travel an exorbitant amount of time to their school of origin is both timeconsuming and stressful. Further, those students who do not qualify as homeless are not protected by McKinney-Vento.

In addition to the logistics of simply getting a child to and from school without adequate transportation, participants in the focus groups also noted the impact of transportation access on a student's ability to stay late after school or a parent's ability to participate fully in the educational experience of their child. For example, one participant noted, "Speaking for Plano ISD, they do have buses that run late. They have a late bus route, but it doesn't take into account...tutorials and things like that. It doesn't take into account sports." So a child's participation in educational supports or extracurricular activities may be limited by their parents' lack of a personal vehicle. This is an added layer of academic and social development that may be hampered by transportation inequity. Furthermore, a district school bus may be available to bring a child to school, but his or her parent is not afforded the same provision. As a result, a parent without personal transportation may be impeded in volunteering at school, eating lunch with their child, attending parent-teacher meetings or participating in PTA. One participant stated, “... One of the things we've learned about some of the public buses from a different perspective as far as getting parents involved in PTA...the stops to the schools aren't always adequate. So it's not a door to door. And so the service isn't as great for the parents' involvement in the child's life. So that's a problem." Research demonstrates the importance of parent involvement in a child's life, which means transportation access is directly linked to this success.

On the later end of the educational spectrum, a few participants also discussed transportation in relation to students attending Collin College. One resident stated, "There's no transportation between the colleges or buses or anything going between the different campuses for the college, Collin College." Though students in the sample discussed the availability of student discounts on bus fares, they also noted that not all of the Collin College campuses are located on a bus line. A shelter employee noted that the shelter provides transportation for a college student in their young adult program to attend class on the Frisco Preston Ridge campus three days per week; however, the student has to pay for an Uber back to the facility. The cost of bus passes or ride services can get expensive for young adults with a limited income. 


\section{Social Activities}

Social events were sparsely mentioned in the focus group discussions; instead, access to basic necessities, such as buying groceries from Wal-Mart, were the primary topic of conversation. Those who did mention access to social activities were either non-EJ residents, were referencing experiences with transportation infrastructure in other states, or were making recommendations about possible improvements to the transportation infrastructure in Collin County. Multiple non-EJ residents reported having ridden the DART train to Dallas for special events or destinations. For many, this was their primary interaction with local public transit. By contrast, one non-EJ participant described the all-encompassing impact of getting his own bus pass as a youth in California: "It led to a ton of opportunities. A ton of freedom...I grew up in the San Fernando valley, so separated by a hill to get where a lot of my friends lived and so to go see them to meet up with them. They weren't going to drive to see me and so I had to go see them. [A bus pass] gave me...freedom, flexibility...[and a] source of dignity." Another non-EJ participant described the commonplace use of public transit to social activities such as restaurants and the theater in New York. Referencing access to social activities in Collin County, a non-EJ participant stated, "Frisco has so many event centers and everything and The Star's up there. But there's no way to get there unless you just Uber, which is super expensive." Another participant suggested implementing special public transit for special occasions, as exists in other larger cities. She stated, "There's some type of bus that will transport for free on certain days for certain big events." Improved transportation infrastructure would make participation in all that Collin County has to offer accessible and affordable for all Collin County residents.

Issues faced by individual residents as a result of the current public transit system

Research Question 3: How do perspectives differ between EJ and non-EJ residents?

Many of the non-EJ focus group participants had little to no first-hand experience with the public transit system. Only one non-EJ participant had significant prior experience riding the bus for three years before she had a personal vehicle. More often the non-EJ participants cited having utilized DART only rarely to travel to Dallas for attractions such as the aquarium, the zoo or another destination in downtown. They described their frequency of public transit use as: "maybe only like twice"; "a handful of times"; and "a long time ago." One non-EJ participant admitted he "didn't realize they don't have buses in Allen" until it was mentioned by a fellow participant during the focus group. This lack of public transit awareness, or regular use, seemed to highlight what another participant referred to as a "massive wealth gap" in Collin County. This individual stated, "You know, if you're wealthy in Collin County, you're going to have cars and have access to all those things [e.g. healthcare, employment]...And if you're not, you're gonna be left behind." Another participant added, "... Not only are you left behind but your children are left behind." Though these non-EJ residents were able to identify multi-faceted challenges faced by Collin County residents lacking material resources, they themselves were most often not personally impacted by them due to having access to personal vehicles. 
One thread that illuminated from the data was the reality of economic disparities between EJ and non-EJ residents of Collin County and perhaps, a lack of consideration of the needs of those in lower- to middle- income brackets. For those with the means, the problems with transportation infrastructure meant very little to their everyday lives, yet for others, the lack of quality transit options impacted nearly every part of their daily lives. One non-EJ participant shared, "....From where I've sat, it seems that the disparity between the people that have the means to have their own transportation and those that don't, seems to have grown. We just haven't necessarily supported the lower to middle income bracket. Do I think that access that eased up for them as a result of the booming economy? I don't think so."

In contrast with the non-EJ participants, EJ residents reported much more personal, ongoing experiences with the public transit system in Collin County. EJ residents spoke both to how they have been directly impacted by inadequacies within the existing public transit system and how their daily lives would be greatly benefited by even small changes to that system. While a couple of these individuals possessed personal vehicles of varying reliability, most relied on walking, biking, sharing rides, riding public transit, or utilizing services such as Lyft/Uber to get around. The most salient finding from responses of EJ residents was the prevalence of additional hardships faced due to inadequate - or non-existent - public transit.

One such hardship for EJ residents was time spent traveling to and from a destination. Numerous participants essentially reported that they had to 'work to get to work' due to locations and spacing of bus stops, infrequency of routes, and the need to piece together multiple forms of transit to arrive at a single destination. One participant without a vehicle reported walking with her baby "six miles from my job to the daycare." This same participant noted that she and her children were sometimes out walking after dark due to lack of public transportation in McKinney. A previously EJ resident of Collin County described her public transit experience: "For me to get to my job, I would have to get up at five o'clock in the morning, catch the bus and would go way out of the way and get on another bus that would bring me way back to where I need to go, and then get on the train, that would take me right down the street to where I needed to be. It was a nightmare. But I did that for three years straight." A Collin County shelter worker described her work with young adults who "rely on public transportation to get them to their jobs or to go to doctor's appointments and that kind of thing." She stated, "It's difficult. I mean, just planning their schedules, having to leave two hours early just to get across town to get to work on time if they're over on the other side of town." Some participants noted that even if they left appropriately early for work, they might still be late due to busses not running on schedule or having to travel considerably out of the way to arrive at a given destination. In one focus group, there was a consensus that the amount of travel time required to complete certain tasks or appointments - for example, obtaining a driver's license - would cause some EJ residents not to even attempt them. Whereas someone with a personal vehicle could complete the task over a lunch break, someone relying on public transit may need a whole day or more for the same task.

Cost was an additional hardship related to transportation, particularly as all EJ residents who participated in the focus groups were living in a shelter and working lower wage jobs or attending school. Residents of a city with no public transit were especially burdened by the cost of not having personal transportation. One EJ participant stated, 
"At this point in my life I can't afford to call Uber or a taxi." A few residents reported saving their earnings to be able to afford to not walk to destinations and yet pointed out that their money would stretch further if other transportation options existed. For example, an EJ participant reported, "...With Uber, l've spent six dollars to go two blocks up the street where I could spend six dollars and ride all day long on the bus." However, even the bus rate was not without complaint. One staff working with EJ youth described the rate for bus passes as "expensive," even with the nonprofit discount.

Cost concerns not only impacted transportation accessibility for EJ residents but also impacted their ability to find housing and maintain gainful employment. Among a number of EJ focus group participants there was a common experience of logistical barriers to upward mobility. One shelter resident stated, "My goal is to get out of here. To find me a place. But on my salary, I can't afford rent in McKinney, and a car. So without public transportation, what do you do?" Another resident noted that her lack of transportation "prohibits me from getting a better job," as she is limited to working at places within walking distance. A third resident discussed the hardships of driving an unreliable vehicle to a new job eight miles away: "I mean if it breaks down once I get out [of the shelter], then I'm gonna fall right back down the rabbit hole again. I'Il lose that job." These individuals wanted to better themselves and to contribute to the community but were stuck in a cycle of interrelated challenges. One of them underscored the importance of reframing attitudes toward "hand-outs" for lower and middle-income residents: "A hand up is providing them transportation so they can get to those jobs...[and] those services that they need to be a part of the community."

In addition to the differences identified above, many common threads also emerged across participants in both the EJ and non-EJ populations. Almost exclusively participants in both groups noted the need for a personal vehicle to navigate life in Collin County. Some variation of "make sure [you] have a car [to live here]" was stated 13 times across the four focus groups. Another shared concern of both populations was increased traffic due to population growth. This was true for both intracity transit and intercity transit within the county. One EJ resident stated, "The main thing you notice [about the economic growth in Collin County] is the traffic. You notice it's getting busier." A participant who works with an EJ population in Plano reflected, "We used to be able to get from McKinney to all the other parts of the county in about 20 minutes. Now we're lucky if we can get to Celina and Wylie in 40, 45 minutes." Another participant spoke to how increased traffic has impacted accessibility of services for both populations:

“...We're hearing complaints from people that do have reliable transportation... They're complaining about the commute. So what used to be a 15 minute commute to the doctor could now be a 35 or 45 minute commute to the doctor. So that's one segment of I think the Collin County population. They have stable transportation and they can get there. Then I think there is a percentage of individuals who struggled to get - to get those basic needs met because their current transportation pool is not that stable and it ebbs and flows and so because there's been an expansion in transportation, it was a challenge prior to the growth and it's an even bigger challenge now because perhaps some of the services may be a little bit further away..." A non-EJ resident described that, in Plano, "Even in the middle of the day when you think it wouldn't be busy, like at noon or...one o'clock, there's still traffic everywhere." 


\subsection{QUANTITATIVE FINDINGS}

\subsection{SURVEY PARTICIPANTS}

In the quantitative portion of this study, the research team conducted a survey to collect information about transportation behaviors (i.e., preferred and actual transportation mode, trip purposes), perceptions and barriers of existing transportation in Collin County. The research team collected 205 responses between May $22^{\text {nd }}$ and July $3^{\text {rd }} 2019$ through an online survey.

The age of the survey respondents ranged from 17 to 98 and the majority $(23.41 \%)$ of the respondents were aged 35-44 years old. The majority of people self-identified as Caucasian (36.36\%) followed by African American (24.75\%), Hispanic (7.58\%), and Asian (2.53\%). Education level varied; the majority (26.83\%) had a college degree, followed by $20.49 \%$ high school degree or equivalent and $17.07 \%$ with some college degree. Over $43 \%$ of the respondents are married (43.72\%) and over $53 \%$ of respondents were employed full time at the time of the survey. Table 2 presents a summary of responders' demographic characteristics.

Table 2 Summary of demographic characteristics of survey responders

\begin{tabular}{|c|c|c|}
\hline Variables & Sub-Categories & $\%(n)$ \\
\hline \multirow{8}{*}{ AGE } & 18-24 Years Older & $9.76 \%(20)$ \\
\hline & 25-34 Years Older & $11.22 \%(23)$ \\
\hline & 35-44 Years Older & $23.41 \%(48)$ \\
\hline & 45-54 Years Older & $22.44 \%(46)$ \\
\hline & 55-64 Years Older & $20.98 \%(43)$ \\
\hline & 65-74 Years Older & $6.34 \%(13)$ \\
\hline & 75 Years and Older & $2.93 \%(6)$ \\
\hline & Missing & $2.93 \%(6)$ \\
\hline \multirow{8}{*}{ ETHNICITY } & African American/Black & $24.75 \%(49)$ \\
\hline & Asian/Pacific islander & $2.53 \%(5)$ \\
\hline & Caucasian/White & $36.36 \%(72)$ \\
\hline & Hispanic/Latino & $7.58 \%(15)$ \\
\hline & Multi-Racial & $5.05 \%(10)$ \\
\hline & Native American & $3.03 \%(6)$ \\
\hline & Other & $14.14 \%(28)$ \\
\hline & prefer not to answer & $6.57 \%(13)$ \\
\hline \multirow{8}{*}{ EDUCATION } & Less than high school & $4.88 \%(10)$ \\
\hline & High school degree or equivalent & $20.49 \%(42)$ \\
\hline & Associates degree & $9.76 \%(20)$ \\
\hline & Some college & $17.07 \%(35)$ \\
\hline & College degree & $26.83 \%(55)$ \\
\hline & Master's degree & $15.61 \%(32)$ \\
\hline & Doctoral degree & $1.95 \%(4)$ \\
\hline & Prefer not to answer & $3.41 \%(7)$ \\
\hline
\end{tabular}




\begin{tabular}{|c|l|c|}
\hline \multicolumn{1}{|c|}{ Variables } & Sub-Categories & \% (n) \\
\hline \hline \multirow{4}{*}{ MARITAL STATUS } & Divorced & $17.59 \%(35)$ \\
\cline { 2 - 3 } & Never Married & $28.14 \%(56)$ \\
\cline { 2 - 3 } & Married & $43.72 \%(87)$ \\
\cline { 2 - 3 } & Separated & $3.02 \%(6)$ \\
\cline { 2 - 3 } & Widowed & $3.52 \%(7)$ \\
\cline { 2 - 3 } & Prefer not to answer & $4.02 \%(8)$ \\
\hline \hline \multirow{5}{*}{ EMPLOYMENT } & Full time employed & $52.79 \%$ \\
& & $1104)$ \\
\cline { 2 - 3 } & Part-time employed & $14.21 \%(28)$ \\
\cline { 2 - 3 } & Unemployed by choice & $15.23 \%(30)$ \\
\cline { 2 - 3 } & Unemployed not by choice & $13.71 \%(27)$ \\
\cline { 2 - 3 } & Prefer not to answer & $4.06 \$(8)$ \\
\hline
\end{tabular}

\subsection{SURVEY DATA ANALYSIS}

The research team identified eight existing transportation modes in Collin County, including DART rail systems, public bus, rid, and car-share, personal vehicle, and active modes of walk and bike, and other. First, the research team compared the transportation choices and use frequency for the eight modes as shown in Figure 12. An overwhelming proportion of the respondents answered that they never used the public transportation systems, ride- or car-share system, and bike. Walk was the only option that the respondents considered to use daily other than a personal vehicle. The percentages of using the DART, public transit, bike, and walk at least once a month were $23 \%, 11 \%$, $16 \%$, and $56 \%$, respectively. 


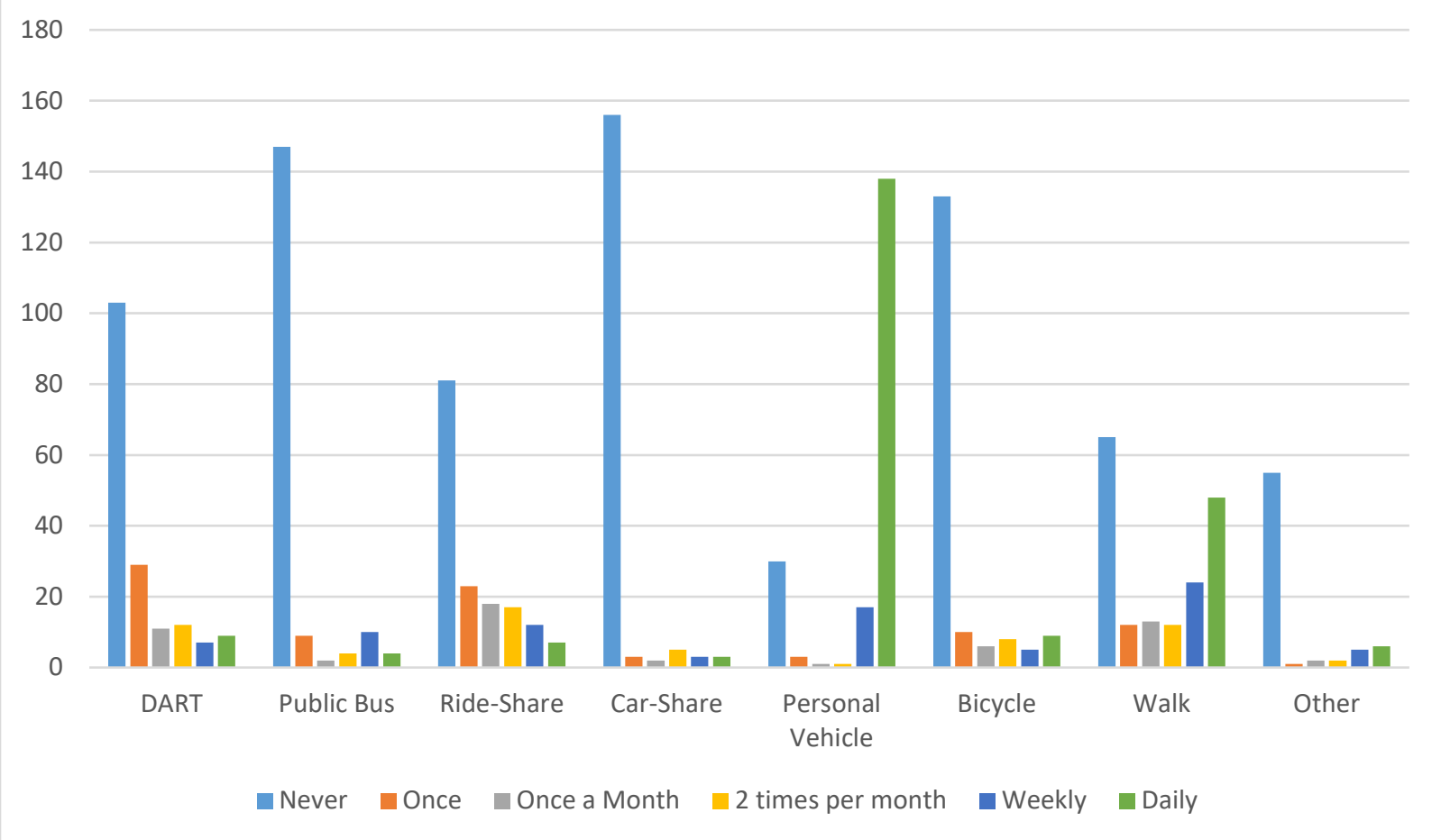

Figure 12 Transportation Mode Choice and use frequency

The research team investigated the transportation mode choice for different sociodemographic groups. The team combined the mode to four categories where active mode includes walk and bike. Table 3 compared the transportation mode by age, education, race, and the number of children of the survey respondents. The team used two education level categories such as associate degree and higher and high school degree or lower. From this analysis, the team defined car-share (e.g., Car2go, ZipCar) and ride-hailing (e.g., Uber and Lyft) modes as shared-mobility service.

The team found that the respondents who are age 25 and over likely used personal cars as their typical mobility option for commute trips. While $86 \%$ of respondents aged $65+$ used personal cars, no one used shared-mobility service or active transportation for their commute trips. On the other hand, younger people were interested in using active transportation as $47 \%$ of young adults choose to walk or bike to get to work. The survey results showed that the respondents who are more educated prefer personal car. More than half of respondents that have high school degree or lower used shared-mobility, public transit, or active transportation. Similarly, only $13 \%$ of White respondents choose shared-mobility service, public transit, and active mode as their commute mode while $32 \%$ of non-White respondents choose these alternate modes. The survey results also showed that $34 \%$ of respondents who do not have children used public transit and active modes for their commute trips, which is much higher proportion than their counterpart $(12 \%)$. 
Table 3 Different transportation mode users for trips to work

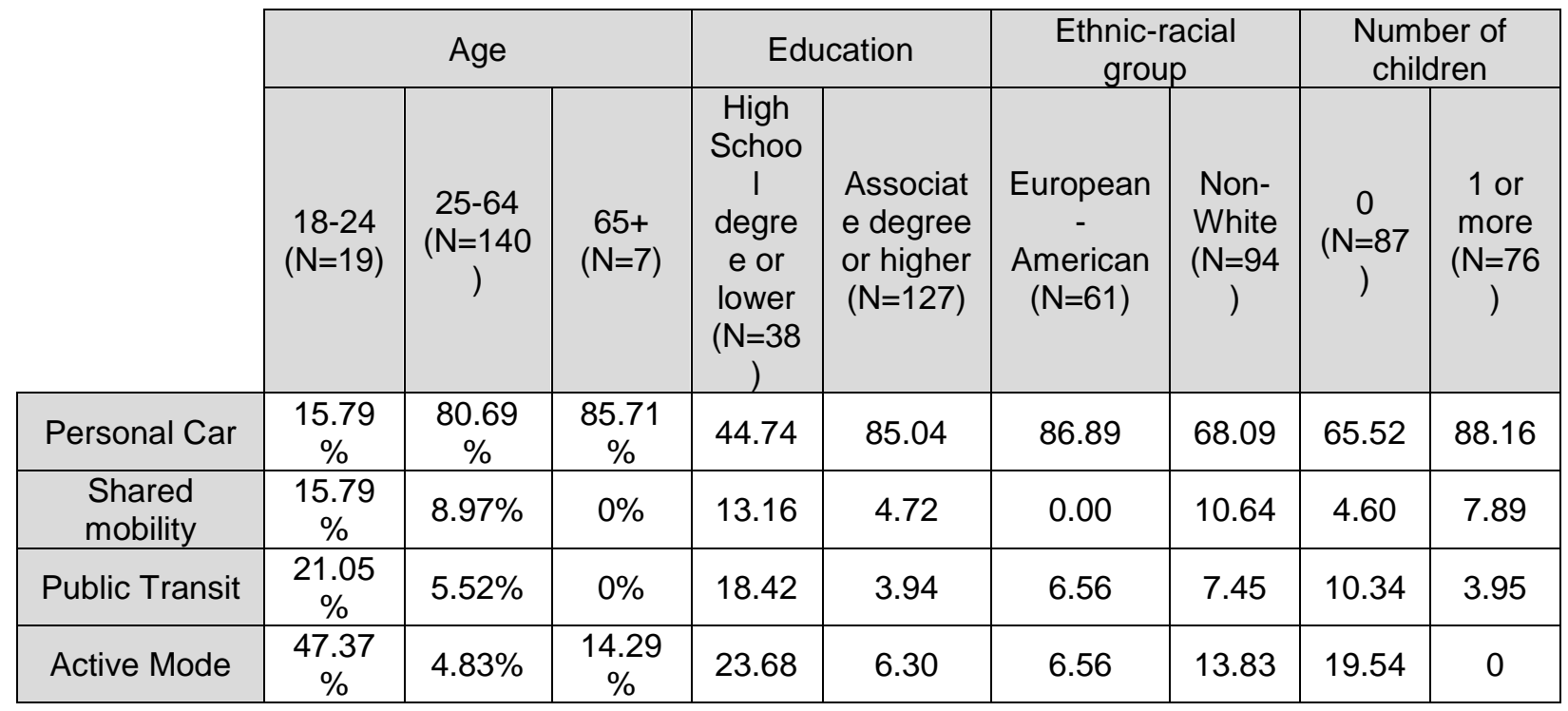

In order to compare the travel mode choice differences between EJ and Non-EJ population, Table 4 compares the mode choice by two racial groups of White and nonWhite. We found a significant difference on personal car use for trips to work in EJ and Non-EJ population (about 55\% and 95\%, respectively). The considerable difference in travel mode choice between white and non-white population was in shared mobility where only EJ non-White group used the service. Public transit and active mode were also used by EJ population more frequently.

Table 4 Comparison of transportation mode between EJ and Non-EJ Population

\begin{tabular}{|c|c|c|c|c|}
\cline { 2 - 5 } \multicolumn{1}{c|}{} & \multicolumn{2}{c|}{ EJ Population } & \multicolumn{2}{c|}{ Non-EJ Population } \\
\cline { 2 - 5 } & $\begin{array}{c}\text { White } \\
(\mathrm{N}=16)\end{array}$ & $\begin{array}{c}\text { Non-White } \\
(\mathrm{N}=59)\end{array}$ & $\begin{array}{c}\text { White } \\
(\mathrm{N}=45)\end{array}$ & $\begin{array}{c}\text { Non-White } \\
(\mathrm{N}=35)\end{array}$ \\
\hline Personal Car & $56.25 \%$ & $52.54 \%$ & $97.78 \%$ & $94.29 \%$ \\
\hline Shared mobility & $0.00 \%$ & $16.95 \%$ & $0.00 \%$ & $0.00 \%$ \\
\hline Public Transit & $25.00 \%$ & $10.17 \%$ & $0.00 \%$ & $2.86 \%$ \\
\hline Active Mode & $18.75 \%$ & $20.34 \%$ & $2.22 \%$ & $2.86 \%$ \\
\hline
\end{tabular}

Although the typical commute mode of transportation largely depends on the availability of the service, the research team investigated how the existing transportation infrastructures and available services meet the expectation that the respondents have for transportation. Tables 5 and 6 compares the typical and preferred mode to work for both EJ and Non-EJ population. The majority of respondents in both groups indicated that they preferred and used a personal vehicle for commute ( $47 \%$ in EJ population and $85 \%$ in Non-EJ population). While only $12.8 \%(\mathrm{~N}=78)$ of the responders in EJ population 
group used public transit as their typical mode for their trips to work, $20.5 \%$ of the respondents would prefer to use either train or bus to get to work if available. On contrary, 15 respondents of EJ population walked or biked to work even though only six of them were satisfied with this option. However, while only two respondents walked or biked to work, four of the respondents prefer to use these modes for their trips.

Table 5 Preferred vs. typical mode of travel to work for EJ population

\begin{tabular}{|c|c|c|c|c|c|c|}
\hline & & \multirow{2}{*}{\multicolumn{4}{|c|}{ Typical Mode to Work }} & \multirow[b]{3}{*}{ Total } \\
\hline & & & & & & \\
\hline & & $\begin{array}{c}\text { Personal } \\
\text { Car }\end{array}$ & $\begin{array}{l}\text { Shared } \\
\text { mobility }\end{array}$ & Public Transit & Active Mode & \\
\hline \multirow{4}{*}{$\begin{array}{c}\text { Preferred } \\
\text { Mode to } \\
\text { Work }\end{array}$} & Personal Car & 37 & 4 & 2 & 7 & 50 \\
\hline & Shared mobility & 0 & 5 & 1 & 0 & 6 \\
\hline & Public Transit & 5 & 2 & 7 & 2 & 16 \\
\hline & Active Mode & 0 & 0 & 0 & 6 & 6 \\
\hline & Total & 42 & 11 & 10 & 15 & \\
\hline
\end{tabular}

Table 6 Preferred vs. typical mode of travel to work for Non-EJ population

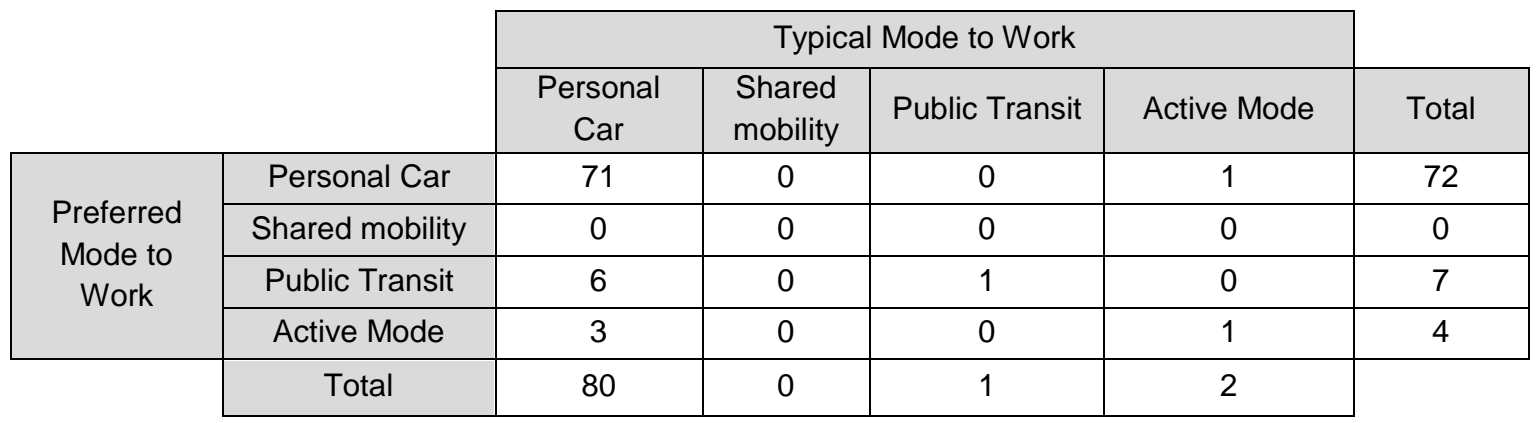

To understand the reasons that the respondents did not use (11 respondents) or prefer public transportation (23 respondents), the research team investigated the perceived efficiency of public transit from the respondents as shown in Table 7 . The results showed that the car drivers tended to perceive public transit not effective while the transit and shared-mobility users likely had a positive perception about the transit service. In particular, about $88 \%$ of shared-mobility users considered public transit moderately or very effective while only $14 \%$ of car drivers considered train or bus services in Collin County effective. 
Table 7 Efficiency of public transit for getting to work according to different mode users

\begin{tabular}{|c|c|c|c|c|c|c|}
\cline { 3 - 7 } \multicolumn{2}{c|}{} & \multicolumn{5}{c|}{ Efficiency of public transit for getting to Work } \\
\cline { 3 - 7 } \multicolumn{1}{c|}{} & $\begin{array}{c}\text { Not } \\
\text { Effective }\end{array}$ & $\begin{array}{c}\text { Slightly } \\
\text { Effective }\end{array}$ & Neutral & $\begin{array}{c}\text { Moderately } \\
\text { Effective }\end{array}$ & $\begin{array}{c}\text { Very } \\
\text { Effective }\end{array}$ \\
\hline \multirow{4}{*}{$\begin{array}{c}\text { Typical } \\
\text { Mode to } \\
\text { Work }\end{array}$} & $\begin{array}{c}\text { Personal Car } \\
(\mathrm{n}=98)\end{array}$ & $68.37 \%$ & $11.22 \%$ & $6.12 \%$ & $4.08 \%$ & $10.20 \%$ \\
\cline { 2 - 7 } & $\begin{array}{c}\text { Shared } \\
\text { mobility(n=8) }\end{array}$ & $12.50 \%$ & $0.00 \%$ & $0.00 \%$ & $25.00 \%$ & $62.50 \%$ \\
\cline { 2 - 7 } & $\begin{array}{c}\text { Public Transit } \\
(\mathrm{n}=11)\end{array}$ & $9.09 \%$ & $9.09 \%$ & $18.18 \%$ & $36.36 \%$ & $27.27 \%$ \\
\cline { 2 - 7 } & $\begin{array}{c}\text { Active Mode } \\
(\mathrm{n}=13)\end{array}$ & $38.46 \%$ & $0.00 \%$ & $7.69 \%$ & $7.69 \%$ & $46.15 \%$ \\
\hline
\end{tabular}

The analysis showed that $37 \%$ of respondents considered that public transit is not effective or slightly effective. To further investigate the factors that caused the negative perceptions about the public transit, the team identified eight transit barriers such as inconvenience of using the transit system, high costs, or a lack of knowledge/understanding of the service. Table 8 compared the ranking of the identified barriers by the users categorized into their major transportation modes to work. In general, inconvenience and lack of access points were among the main barriers for the all users, except for the shared-mobility users who believed that costs, wait times and lack of knowledge are the main negative factors discouraging them to use public transit. However, the public transit users considered costs as more important barriers to use the system, followed by inconvenience and access points.

Table 8 Barriers to using public transit for different users

\begin{tabular}{|c|c|c|c|c|c|}
\hline Ranking & $\begin{array}{c}\text { All users } \\
(\mathrm{N}=166)\end{array}$ & $\begin{array}{c}\text { Transit users } \\
(\mathrm{N}=12)\end{array}$ & $\begin{array}{c}\text { Drivers } \\
(\mathrm{N}=126)\end{array}$ & $\begin{array}{c}\text { Shared- } \\
\text { mobility } \\
\text { users }(\mathrm{N}=11)\end{array}$ & $\begin{array}{c}\text { Active- } \\
\text { commuter } \\
(\mathrm{N}=17)\end{array}$ \\
\hline 1 & $\begin{array}{c}\text { Inconvenience } \\
(21.79 \%)\end{array}$ & Costs $(26.09 \%)$ & $\begin{array}{c}\text { Inconvenienc } \\
\mathrm{e}(24.01 \%)\end{array}$ & $\begin{array}{c}\text { Costs } \\
(25.93 \%)\end{array}$ & $\begin{array}{c}\text { Access Points } \\
(18.92 \%)\end{array}$ \\
\hline 2 & $\begin{array}{c}\text { Access Points } \\
(17.65 \%)\end{array}$ & $\begin{array}{c}\text { Inconvenience } \\
(13.04 \%)\end{array}$ & $\begin{array}{c}\text { Access } \\
\text { Points } \\
(19.35 \%)\end{array}$ & $\begin{array}{c}\text { Wait times } \\
(18.52 \%)\end{array}$ & Costs (18.92\%) \\
\hline 3 & $\begin{array}{c}\text { Wait times } \\
(14.16 \%)\end{array}$ & $\begin{array}{c}\text { Access Points } \\
(13.04 \%)\end{array}$ & $\begin{array}{c}\text { Wait times } \\
(14.70 \%)\end{array}$ & $\begin{array}{c}\text { Lack of } \\
\text { Knowledge } \\
(14.81 \%)\end{array}$ & $\begin{array}{c}\text { Inconvenience } \\
(16.22 \%)\end{array}$ \\
\hline 5 & $\begin{array}{c}\text { Lack of } \\
\text { Knowledge }\end{array}$ & $\begin{array}{c}\text { Wait times } \\
(11.76 \%)\end{array}$ & $\begin{array}{c}\text { Lack of } \\
\text { Knowledge } \\
(12.19 \%)\end{array}$ & $\begin{array}{c}\text { Inconvenienc } \\
\text { e (14.81\%) }\end{array}$ & $\begin{array}{c}\text { Wait times } \\
(13.51 \%)\end{array}$ \\
\hline 6 & Costs $(10.24 \%)$ & Other (13.04\%) & $\begin{array}{c}\text { Other } \\
(8.96 \%)\end{array}$ & $\begin{array}{c}\text { Access } \\
\text { Points } \\
(11.11 \%)\end{array}$ & Other (13.51\%) \\
\hline 5 & Other (9.5\%) & $\begin{array}{c}\text { Safety } \\
(13.04 \%)\end{array}$ & $\begin{array}{c}\text { Prefer not to } \\
\text { use (8.96\%) }\end{array}$ & $\begin{array}{c}\text { Safety } \\
(11.11 \%)\end{array}$ & Safety (8.11\%) \\
\hline
\end{tabular}




\begin{tabular}{|c|c|c|c|c|c|}
\hline Ranking & $\begin{array}{c}\text { All users } \\
(\mathrm{N}=166)\end{array}$ & $\begin{array}{c}\text { Transit users } \\
(\mathrm{N}=12)\end{array}$ & $\begin{array}{c}\text { Drivers } \\
(\mathrm{N}=126)\end{array}$ & $\begin{array}{c}\text { Shared- } \\
\text { mobility } \\
\text { users (N=11) }\end{array}$ & $\begin{array}{c}\text { Active- } \\
\text { commuter } \\
(\mathrm{N}=17)\end{array}$ \\
\hline 7 & Safety $(7.84 \%)$ & $\begin{array}{c}\text { Lack of } \\
\text { Knowledge } \\
(4.35 \%)\end{array}$ & $\begin{array}{c}\text { Safety } \\
(6.81 \%)\end{array}$ & $\begin{array}{c}\text { Other } \\
(3.70 \%)\end{array}$ & $\begin{array}{c}\text { Lack of } \\
\text { Knowledge } \\
(5.41 \%)\end{array}$ \\
\hline 8 & $\begin{array}{c}\text { Prefer not to use } \\
(7.41 \%)\end{array}$ & $\begin{array}{c}\text { Prefer not to } \\
\text { use (4.35\%) }\end{array}$ & $\begin{array}{c}\text { Costs } \\
(5.02 \%)\end{array}$ & $\begin{array}{c}\text { Prefer not to } \\
\text { use (0\%) }\end{array}$ & $\begin{array}{c}\text { Prefer not to } \\
\text { use (5.41\%) }\end{array}$ \\
\hline
\end{tabular}

The research team analyzed the transportation mode choice by purpose of trips: mandatory, healthcare, discretionary and other purposes. Mandatory trips include work or school trips, which are performed on a daily basis with fixed trip origin/destination locations. Healthcare trips represent medical or childcare trips, and discretionary trips include trips to shopping areas, park and entertainment destinations. Other trips include trips to other destinations such as religious locations. As shown in Table 9, or all the purposes of trips, a personal car is the most commonly chosen mode especially for healthcare and other purpose trips. Approximately 3-5\% of respondents used shared vehicles for their trips. The respondents tended to use public transit for mandatory and healthcare trips (18\% and $17 \%$, respectively) that represent a regular and fixed scheduled trip, compared to discretionary and other trips (13\% and $11 \%$, respectively). Nearly $13 \%$ of the respondents chose active modes of travel for discretionary trips (13\%), which is comparable to the respondents who use public transit.

Table 9 Mode choice vs. purpose of trips

\begin{tabular}{|c|c|c|c|c|c|}
\cline { 3 - 5 } \multicolumn{2}{c|}{} & \multicolumn{4}{c|}{ Purpose of trip } \\
\cline { 3 - 6 } \multicolumn{2}{c|}{} & Mandatory & Healthcare & $\begin{array}{c}\text { Discretionar } \\
y\end{array}$ & Other \\
\hline \multirow{3}{*}{$\begin{array}{c}\text { Mode of } \\
\text { travel }\end{array}$} & Personal Car & $70.01 \%$ & $77.54 \%$ & $68.44 \%$ & $82.76 \%$ \\
\cline { 2 - 6 } & $\begin{array}{c}\text { Shared } \\
\text { mobility }\end{array}$ & $4.61 \%$ & $4.27 \%$ & $5.65 \%$ & $3.26 \%$ \\
\cline { 2 - 6 } & Public Transit & $17.56 \%$ & $16.58 \%$ & $12.59 \%$ & $11.32 \%$ \\
\cline { 2 - 6 } & Active Mode & $7.83 \%$ & $1.6 \%$ & $13.32 \%$ & $2.66 \%$ \\
\hline
\end{tabular}

The team investigated the relationships between the length of residence in Collin County and the typical mode to work to understand how the length of residence affect their transportation mode choice. Based on the recent inflow of population and employment in Collin County, the team categorized the length of residence into less than one year, one to five years, six to 15 years, and more than 15 years. Table 10 compared the transportation mode choice to work between the groups. Interestingly, the transportation options of the new residents of Collin County (less than 1 year) were evenly distributed, and ranged from $20 \%$ to $33 \%$ for all given options among personal car, shared mobility, public transit, and active mode, while other groups dominantly used the personal vehicles over other options. 
Table 10 Length of residence in Collin County of different transportation mode users for trips to work

\begin{tabular}{|c|c|c|c|c|c|}
\hline & & \multicolumn{4}{|c|}{ Length of residence } \\
\hline & & $\begin{array}{c}\text { Less than } 1 \\
\text { year } \\
(\mathrm{N}=30)\end{array}$ & $\begin{array}{c}1 \text { to } 5 \\
\text { years } \\
(\mathrm{N}=31)\end{array}$ & $\begin{array}{l}6 \text { to } 15 \\
\text { years } \\
(\mathrm{N}=46)\end{array}$ & $\begin{array}{c}\text { More than } 15 \\
\text { years } \\
(\mathrm{N}=59)\end{array}$ \\
\hline \multirow{4}{*}{$\begin{array}{l}\text { Typical } \\
\text { Mode to } \\
\text { Work }\end{array}$} & Personal Car & $33.33 \%$ & $83.87 \%$ & $84.78 \%$ & $86.44 \%$ \\
\hline & $\begin{array}{l}\text { Shared } \\
\text { mobility }\end{array}$ & $20.00 \%$ & $3.23 \%$ & $6.52 \%$ & $1.69 \%$ \\
\hline & $\begin{array}{l}\text { Public } \\
\text { Transit }\end{array}$ & $20.00 \%$ & $6.45 \%$ & $4.35 \%$ & $3.39 \%$ \\
\hline & Active Mode & $26.67 \%$ & $6.45 \%$ & $4.35 \%$ & $8.47 \%$ \\
\hline
\end{tabular}

Table 11 showed how the length of residence in Collin County affect their perceptions about public transit. The eight barriers identified earlier were compared by the length of residence. Inconvenience were chosen as the most significant barrier for all residents except those who lived in Collin County between 1 and 5 years. From the second most important to the least significant barriers, the respondents' opinions varied. Lack of knowledge, cost, and wait time were identified as the most important barriers for the new residents whereas access points along with inconvenience were critical barriers to using public transit for those who live more than 6 years in Collin County.

Table 11 Barriers to using public transit and length of residence in Collin County

\begin{tabular}{|c|c|c|c|c|}
\hline Ranking & $\begin{array}{l}\text { Less than } 1 \text { year } \\
\qquad(\mathrm{N}=32)\end{array}$ & $\begin{array}{c}1 \text { to } 5 \text { years } \\
(N=36)\end{array}$ & $\begin{array}{l}6 \text { to } 15 \text { years } \\
(N=58)\end{array}$ & $\begin{array}{l}\text { More than } 15 \\
\text { years }(N=72)\end{array}$ \\
\hline 1 & $\begin{array}{c}\text { Inconvenience } \\
(19.48 \%)\end{array}$ & $\begin{array}{l}\text { Wait times } \\
(18.92 \%)\end{array}$ & $\begin{array}{c}\text { Inconvenience } \\
(23.31 \%)\end{array}$ & $\begin{array}{c}\text { Inconvenience } \\
(23.43 \%)\end{array}$ \\
\hline 2 & $\begin{array}{c}\text { Lack of knowledge } \\
(16.88 \%)\end{array}$ & $\begin{array}{c}\text { Inconvenience } \\
(16.22 \%)\end{array}$ & $\begin{array}{c}\text { Access Points } \\
(21.05 \%)\end{array}$ & $\begin{array}{c}\text { Access Points } \\
(20.57 \%)\end{array}$ \\
\hline 3 & Costs (15.58\%) & $\begin{array}{c}\text { Lack of knowledge } \\
(16.22 \%)\end{array}$ & Other $(12.78 \%)$ & $\begin{array}{c}\text { Wait times } \\
(14.86 \%)\end{array}$ \\
\hline 4 & Wait times (14.29\%) & $\begin{array}{c}\text { Access Points } \\
(14.86 \%)\end{array}$ & \multirow{3}{*}{$\begin{array}{c}\text { Costs, } \\
\text { Wait times, and } \\
\text { Lack of } \\
\text { knowledge } \\
(10.53 \%)\end{array}$} & \multirow{3}{*}{$\begin{array}{l}\text { Costs, Safety, } \\
\text { and } \\
\text { Lack of } \\
\text { knowledge } \\
(8.57 \%)\end{array}$} \\
\hline 5 & Safety (12.99\%) & $\begin{array}{c}\text { Prefer not to use } \\
(13.51 \%)\end{array}$ & & \\
\hline 6 & $\begin{array}{c}\text { Access Points } \\
(9.09 \%)\end{array}$ & Other $(9.46 \%)$ & & \\
\hline 7 & Other $(6.49 \%)$ & Costs $(8.11 \%)$ & Safety $(6.77 \%)$ & $\begin{array}{c}\text { Prefer not to } \\
\text { use }(8 \%)\end{array}$ \\
\hline 8 & $\begin{array}{c}\text { Prefer not to use } \\
(5.19 \%)\end{array}$ & Safety $(2.70 \%)$ & $\begin{array}{l}\text { Prefer not to } \\
\text { use }(4.51 \%)\end{array}$ & Other $(7.43 \%)$ \\
\hline
\end{tabular}




\subsection{CONCLUSION}

Economic growth is often linked with increased access employment, housing, healthcare, education, and other outcomes. However, when such a "boom" is not also met with commensurate improvements in transportation infrastructure, residents of booming cities often fail to gain access to the positive benefits of the boom. This is particularly true for environmental justice (EJ) populations, but can also be true of nonEJ populations who must also use transportation infrastructure for access. As cities across the united states grapple with how to keep pace with economic growth, it is crucial that consideration of all residents becomes part of the transportation infrastructure planning.

There are several key strengths of this study. First, the research design (a mixed methods, sequential exploratory design) allowed us to both measure in-depth perspectives of the voices of the county's residents, as well as bolster preliminary themes with survey data that is able to quantify some of the perspectives, desires, and challenges as viewed by Collin County residents.

The main focus of the study was the perspectives of whether transportation infrastructure has kept pace with the economic boom in the county. Overwhelmingly, both EJ and non-EJ participants felt that transportation infrastructure was severely lacking with respect to keeping pace with the economic boom. The qualitative data describe the increased travel time, limited access to high speed transit options, busing, and ride share options. The quantitative data also suggest such mismatch between the many burgeoning opportunities and the ability to use existing transportation infrastructure to access them.

Additionally, the study focused on how the match between improvements to transportation infrastructure and economic boom has affected access to basic services. According to participants, the qualitative data suggest that this has resulted in extreme challenges with access to basic needs like healthcare, housing, employment, and education. The quantitative findings suggest that the majority of respondents use their own personal vehicles and believe the inconvenience of public transit and ride share options are too high to consider the transportation infrastructure effective. Those who are new to the county would be interested in using public transit options and ride share if available with more convenient stops

Thirdly, the study compared views between EJ populations and non-EJ populations to see whose voices are being heard in making transportation decisions. Both EJ participant and non-EJ participants overwhelmingly agreed that inconvenience is a deterrent from using public transit in the county, although those EJ populations without access to their own car were more negatively affected in access to healthcare, housing, employment, and education. For EJ participants, there was a preference for using public transportation if it was available and the usage numbers are more a reflection of the 
lack of availability than preference. Even with this preference, however, those that used public transportation thought costs of the transportation were a barrier to effective use.

Lastly, the study mapped transit patterns to analyze how transportation usage overlaps with socioeconomic status. Results indicated that as transportation infrastructure in the form of tollway roads increased, so did population density, job density, and percentage of minority population. These came with a corresponding decrease in poverty level.

Several limitations of the study results exist. First, there was limited variability in the age of the EJ focus group participants, with $80 \%$ being between the ages of $18-24$, this does not capture a breadth of age ranges and experiences. However, the survey asks similar focus group questions and did have a broad age range. Additionally, each city within the county did not have representation in the survey, thereby limiting the scope of the perspectives included in the study. 


\subsection{REFERENCES}

Brown, R. B., Geersten, H. R., \& Krannich, R. S. (1989). Community satisfaction and social integration in a boomtown: A longitudinal analysis. Rural Sociology, 54(4), 568-587.

Carlsen, B., \& Glenton, C. (2011). What about N? A methodological study of samplesize reporting in focus group studies. BMC medical research methodology, 11(1), 26.

Creswell, J. W., Klassen, A. C., Plano Clark, V. L., \& Smith, K. C. (2011). Best practices for

mixed methods research in the health sciences. Bethesda (Maryland): National Institutes of Health, 2094-2103.

Cohen, J. (1992). A power primer. Quantitative Methods in Psychology, 112(1), 155 159.

Mayr, S., Erdfelder, E., Buchner, A., \& Faul, F. (2007). A short tutorial

of GPower. Tutorials in Quantitative Methods for Psychology, 3(2), 51-59.

Morrison, T. H., Wilson, C., \& Bell, M. (2012). The role of private corporations in regional planning and development: opportunities and challenges for the governance of housing and land use. Journal of Rural Studies, 28(4), 478-489.

Murphy, T., Brannstrom, C., Fry, M., \& Ewers, M. (2018). Economic-development stakeholder perspectives on boomtown dynamics in the Eagle Ford Shale, Texas. Geographical Review, 108(1), 24-44.

Nagle, B., \& Williams, N. (n.d.). Methodology brief: Introduction to focus groups. Center for Assessment, Planning and Accountability, 1-12.

U.S. Department of Transportation. (2012). Environmental justice policy guidance for federal transit administration recipients. Retrieved

from: https://www.transit.dot.gov/sites/fta.dot.gov/files/docs/FTA EJ Circular 7.1 4-12 FINAL.pdf

Van Horn, P. S., Green, K. E., \& Martinussen, M. (2009). Survey response rates and survey administration in counseling and clinical psychology. Educational and Psychological Measurement, 69(3), 389-403. 


\subsection{APPENDICES}

APPENDIX A 
Institutional Review Board

Notification of Exemption per Revised Common Rule

Federally Funded Study

February 20, 2019

Dr. Landel Crutchfield

Sichool of Social Work

The University of Texas at Arlington

Box 19129

Protocol Number: $\quad$ 2019-0129

Protocol Title: $\quad$ Promoting Environmental Justice Populations' Access to Opportunities within Suburbon Boomtowns: An interdisciplinary, Mixed-Methods Approach to Addressing infrostructure Needs

Federal Funding Source: NITC

Mentis Bluesheet Number: 2017-609-S14

\section{EXEMPTION DETERMINATION}

The UT Arlington Institutional Review Board (IRB) Chair, or designee, has reviewed the above referenced study and found that it qualified for exemption under the federal guidelines for the protection of human subjects as referenced at Title 45CFR Part 46.104(d) under category (2])(ii).

- (2) Research that only includes interactions involving educational tests (cognitive, diagnostic, aptitude, achievement), survey procedures, interview procedures, or observation of public behavior (including visual or auditory recording) if at least one of the following criteria is met: (i) The information obtained is recorded by the investigator in such a manner that the identity of the human subjects cannot readily be ascertained, directly or through identifiers linked to the subjects; or (ii) Any disclosure of the human subjects' responses cutside the research would not reasonably place the subjects at risk of crimina or civil liability or be damaging to the subjects' financial standing, employability, educ ational advancement, or reputation.

You are therefore authorized to begin the research as of February 19, 2019.

Please be advised that as the Principal Investigator, you are required to report local adverse (unanticipated) events to The UT Arlington Office of Research Administration; Regulatory Services within 24 hours of the cccurrence or upon acknowledgement of the occurrence.

Additionally, pursuant to Title 45 CFR 46.108(a)(3)(iii), all proposed changes must be submitted via the electronic submission system and approved by the IRB or designee prior to implementation except when necessary to eliminate immediate hazards to the subject. Modific ations include but are not limited to: Changes in protocol personnel, changes in proposed study procedures, and/or

REGULATORY SERYICE: SERYICES
The Uniwera liy of Texas at Aplingtan, Center For Innovation 202 E. Border Street, Ste. 300 . Aningtom, Texas 76010 , Boxolig198

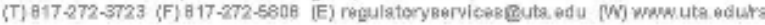




\section{A UNIVERITY OP OFFICE OF RESEARCH ADMINISTRATION TEXAS REGULATORY SERVICES}

updates to data collection instruments. Failure to obtain prior approval for modific at ions is considered an issue of non-compliance and will be subject to review and deliberation by the IRB which could result in the suspension/termination of the protocol.

Finally, all investigators and personnel working on the protocol must be added to the study via a modification request in the electronic system and have documented Human Subjects Protection iHSP) training on file. HSP completion certificates remain valid for 3 years from the completion date.

The UT Arlington Office of Research Administration; Regulatory Services appreciates your continuing commitment to the protection of human research subjects. Should you have questions or require further assistance, please contact Regulatory Services at regulatorservices@uta.edu of $317-272-3723$

REGULATORY SERYICES SERYICES
The Univera liy or Texas at Arl ngtan, Center for Innovation 202 E. Border Street, Ste. 300 , Arlington, Texas 76010, Boxw19198

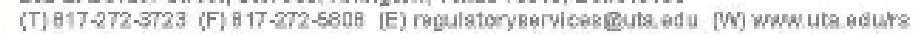




\section{Appendix B}

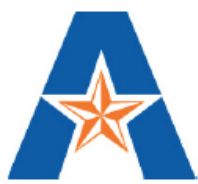

\section{The University of Texas at Arlington (UTA) \\ Informed Consent for Studies with Adults}

\section{TITLE OF RESEARCH PROJECT}

"Helping Environmental Justice Populations Maintain Access to Opportunities in a Boomtown: An Interdisciplinary, Mixed-Methods Approach to Addressing Infrastructure Needs"

\section{RESEARCH TEAM}

Jandel Crutchfield, PhD, LCSW, 225-06-1072, jandel.crutchfield@uta.edu

Courtney Cronley, Phd, cronley@uta.edu

Kate Hyun, kate.hyun@uta.edu

\section{IMPORTANT INFORMATION ABOUT THIS RESEARCH PROJECT}

The research team above is conducting a research study about transportation in Collin County, Texas. The purpose of this study is to better understand the level of access to important services in Collin County like healthcare, education, housing, and employment. You can choose to participate in this research study if you live in Collin County, Texas; speak and read English, are 18 years of age or older, and need transportation assistance to get access to services including healthcare, housing, education, and employment.

You might want to participate in this study if you want to contribute your perspective to a scientific study involving transportation needs in Collin County. However, you might not want to participate in this study if you do not have the time to attend a 1 hour focus group.

This study has been reviewed and approved by an Institutional Review Board (IRB). An IRB is an ethics committee that reviews research with the goal of protecting the rights and welfare of human research subjects. Your most important right as a human subject is informed consent. You should take your time to consider the information provided by this form and the research team, and ask questions about anything you do not fully understand before making your decision about participating.

\section{TIME COMMITMENT}

You are being asked to participate in one (1) focus group. Focus groups may last approximately one (1) hour. These will be conducted in February or March of 2019.

\section{RESEARCH PROCEDURES}

If you decide to participate in this research study, this is the list of activities that we will ask you to perform as part of the research:

1. Read through this Informed Consent and talk with the research team to make sure that any questions you may have are answered; then make your choice about whether to participate.

2. If you agree to participate, you will be asked to attend a 1 hour focus group at a location convenient to you in Collin County.

3. As a research participant, we are asking you to participate in one (1) focus group. During the focus group, the researcher will ask you and other participants questions about your perception of transportation infrastructure in Collin County and how this

IRB Approval Date: 2/19/2019

v. 2019-0129 


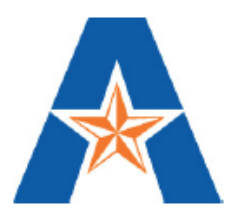

\section{The University of Texas at Arlington (UTA)}

\section{Informed Consent for Studies with Adults}

impacts your access to services like housing, healthcare, education, and employment.

\section{If audio/visual recordings will be used}

The focus group will be audio recorded using an encrypted handheld digital recorder. After the interview, the recording will be transcribed, which means they will be typed exactly as they were recorded, word-for-word, by Rev.com.

\section{POSSIBLE BENEFITS}

If you take part in this project, there may or may not be a direct benefit to you. We hope that your answers will influence the recommendations made to the Collin County Homeless Coalition. This is also an opportunity for you to make your voice heard and to express any concerns regarding transportation in Collin County.

\section{POSSIBLE RISKS/DISCOMFORTS}

Some questions and responses may be sensitive. If you feel upset or uncomfortable, please tell the researcher. We will provide you with a counselor or a referral in case you are upset during or after the study. You have the right to refuse to answer any question and to quit the study at any time with no consequence.

\section{COMPENSATION}

You will be given one (1) $\$ 5$ gift card to Walmart for your time. This will be given to you immediately following the end of the focus group.

The Internal Revenue Service (IRS) considers all payments made to research subjects to be taxable income. Your personal information, including your name, address, and social security number, may be acquired from you and provided to UTA's accounting office for the purpose of payment. If your total payments for the year exceed $\$ 600.00$, UTA will report this information to the IRS as income and you will receive a Form 1099 at the end of the year. If you receive less than $\$ 600.00$ total for payments in a year, you are personally responsible for reporting the payments to the IRS.

\section{ALTERNATIVE OPTIONS}

There are no alternative options offered for this study.

\section{CONFIDENTIALITY}

The research team is committed to protecting your rights and privacy as a research subject. All paper and electronic data collected from this study will be stored in a secure location on the UTA campus and/or a secure UTA server for at least three (3) years after the end of this research. The recordings will be kept with the other electronic data in a secure UTA Box account for the duration of the study.

The results of this study may be published and/or presented without naming you as a participant. The data collected about you for this study may be used for future research studies IRB Approval Date: 2/19/2019

v. 2019-0129 


\section{The University of Texas at Arlington (UTA) Informed Consent for Studies with Adults}

that are not described in this consent form. If that occurs, an IRB would first evaluate the use of any information that is identifiable to you, and confidentiality protection would be maintained.

While absolute confidentiality cannot be guaranteed, the research team will make every effort to protect the confidentiality of your records as described here and to the extent permitted by law. In addition to the research team, the following entities may have access to your records, but only on a need-to-know basis: the U.S. Department of Health and Human Services and the FDA (federal regulating agencies), the reviewing IRB, and sponsors of the study.

\section{CONTACT FOR QUESTIONS}

Questions about this research study or reports regarding an injury or other problem may be directed to Jandel Crutchfield, jandel.crutchfield@uta.edu, 225-206-1072 Any questions you may have about your rights as a research subject or complaints about the research may be directed to the Office of Research Administration; Regulatory Services at 817-272-3723 or regulatoryservices@uta.edu.

\section{CONSENT}

By signing this form, you are confirming that you understand the study's purpose, procedures, potential risks, and your rights as a research subject. By agreeing to participate, you are not waiving any of your legal rights. You can refuse to participate or discontinue participation at any time, with no penalty or loss of benefits that you would ordinarily have. Please sign below if you are at least 18 years of age and voluntarily agree to participate in this study.

SIGNATURE OF VOLUNTEER

\section{DATE}

*If you agree to participate, please provide the signed copy of this consent form to the research team. They will provide you with a copy to keep for your records.

IRB Approval Date: 2/19/2019

v. 2019-0129 


\section{Appendix C}

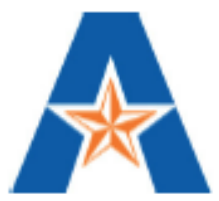

\section{The University of Texas at Arlington (UTA) Informed Consent for Studies with Adults}

TITLE OF RESEARCH PROJECT

"Helping Environmental Justice Populations Maintain Access to Opportunities in a Boomtown: An Interdisciplinary, Mixed-Methods Approach to Addressing Infrastructure Needs"

\section{RESEARCH TEAM}

Jandel Crutchfield, PhD, LCSW, 225-06-1072, jandel.crutchfield@uta.edu

Courtney Cronley, Phd, cronley@uta.edu

Kate Hyun, kate.hyun@uta.edu

\section{IMPORTANT INFORMATION ABOUT THIS RESEARCH PROJECT}

The research team above is conducting a research study about transportation in Collin County, Texas. The purpose of this study is to better understand the level of access to important services in Collin County like healthcare, education, housing, and employment. You can choose to participate in this research study if you live in Collin County, Texas; speak and read English, are 18 years of age or older, and need transportation assistance to get access to services including healthcare, housing, education, and employment.

You might want to participate in this study if you want to contribute your perspective to a scientific study involving transportation needs in Collin County. However, you might not want to participate in this study if you do not have the time to complete a 30 minute survey.

This study has been reviewed and approved by an Institutional Review Board (IRB). An IRB is an ethics committee that reviews research with the goal of protecting the rights and welfare of human research subjects. Your most important right as a human subject is informed consent. You should take your time to consider the information provided by this form and the research team, and ask questions about anything you do not fully understand before making your decision about participating.

\section{TIME COMMITMENT}

You are being asked to participate in one (1) online survey. The survey will last no longer than 30 minutes. These will be conducted in April and May of 2019.

\section{RESEARCH PROCEDURES}

If you decide to participate in this research study, this is the list of activities that we will ask you to perform as part of the research:

1. Read through this Informed Consent and talk with the research team to make sure that any questions you may have are answered; then make your choice about whether to participate.

2. If you agree to participate, you will be asked to complete a $\mathbf{3 0}$ minute survey online.

3. As a research participant, we are asking you to participate in one (1) online survey. The researcher will meet with you to complete the survey. It will contain questions about your perception of transportation infrastructure in Collin County and how this impacts your access to services like housing, healthcare, education, and

IRB Approval Date: 2/19/2019 


\section{The University of Texas at Arlington (UTA)}

\section{Informed Consent for Studies with Adults}

employment.

\section{POSSIBLE BENEFITS}

If you take part in this project, there may or may not be a direct benefit to you. We hope that your answers will influence the recommendations made to the Collin County Homeless Coalition. This is also an opportunity for you to make your voice heard and to express any concerns regarding transportation in Collin County.

\section{POSSIBLE RISKS/DISCOMFORTS}

Some questions and responses may be sensitive. If you feel upset or uncomfortable, please tell the researcher. We will provide you with a counselor or a referral in case you are upset during or after the study. You have the right to refuse to answer any question and to quit the study at any time with no consequence.

\section{COMPENSATION}

You will be given one (1) $\$ 5$ gift card to Walmart for your time. This will be given to you immediately following the completion of the survey.

The Internal Revenue Service (IRS) considers all payments made to research subjects to be taxable income. Your personal information, including your name, address, and social security number, may be acquired from you and provided to UTA's accounting office for the purpose of payment. If your total payments for the year exceed $\$ 600.00$, UTA will report this information to the IRS as income and you will receive a Form 1099 at the end of the year. If you receive less than $\$ 600.00$ total for payments in a year, you are personally responsible for reporting the payments to the IRS.

\section{ALTERNATIVE OPTIONS}

There are no alternative options offered for this study.

\section{CONFIDENTIALITY}

The research team is committed to protecting your rights and privacy as a research subject. All paper and electronic data collected from this study will be stored in a secure location on the UTA campus and/or a secure UTA server for at least three (3) years after the end of this research. The recordings will be kept with the other electronic data in a secure UTA Box account for the duration of the study.

The results of this study may be published and/or presented without naming you as a participant. The data collected about you for this study may be used for future research studies that are not described in this consent form. If that occurs, an IRB would first evaluate the use of any information that is identifiable to you, and confidentiality protection would be maintained.

While absolute confidentiality cannot be guaranteed, the research team will make every effort to protect the confidentiality of your records as described here and to the extent permitted by law. In addition to the research team, the following entities may have access to your records,

IRB Approval Date: 2/19/2019

v. 2019-0129 


\section{The University of Texas at Arlington (UTA)}

\section{Informed Consent for Studies with Adults}

but only on a need-to-know basis: the U.S. Department of Health and Human Services and the FDA (federal regulating agencies), the reviewing IRB, and sponsors of the study.

CONTACT FOR QUESTIONS

Questions about this research study or reports regarding an injury or other problem may be directed to Jandel Crutchfield, jandel.crutchfield@uta.edu, 225-206-1072 Any questions you may have about your rights as a research subject or complaints about the research may be directed to the Office of Research Administration; Regulatory Services at 817-272-3723 or regulatoryservices@uta.edu.

\section{CONSENT}

By signing this form, you are confirming that you understand the study's purpose, procedures, potential risks, and your rights as a research subject. By agreeing to participate, you are not waiving any of your legal rights. You can refuse to participate or discontinue participation at any time, with no penalty or loss of benefits that you would ordinarily have. Please sign below if you are at least 18 years of age and voluntarily agree to participate in this study.

SIGNATURE OF VOLUNTEER

DATE

*If you agree to participate, please provide the signed copy of this consent form to the research team. They will provide you with a copy to keep for your records. 


\section{Appendix D}

In Person Focus Group protocol for EJ population

Hello, my name is (name of researcher). You are logged in today for our discussion regarding Transportation Infrastructure in Collin County. We will begin by reviewing the informed consent together, and if you would like to continue participating in the research, we will ask for your verbal or written agreement to participate. (Researcher will read informed consent, share on screen, and ask for each participant to provide written or oral consent). We ask that all participants keep the information discussed in our session confidential although we cannot promise confidentiality. This is a reminder that you do not have to disclose your actual name or other identifying information and you can withdraw from participation at any time. This information will not be linked to you after the focus group.

\section{Introductions}

- We welcome you this group of residents. Each of you is a resident of Collin County and as such, your voices about transportation in this county are very important to us.

Roles related to transportation

- How do you use public transportation systems in Collin County?

- How do you see your role as related to transportation infrastructure in Collin County? Are you a consumer or decision maker? Please describe.

Perspectives on Economic Growth

- How would you describe the economic growth in Collin County over the last 5 years? Has it been fast or slow, large or small, etc. Give examples of what you have observed?

Perspectives on Transportation Infrastructure

- How well do you think residents of Collin County can access services like doctors' offices, schools, jobs, and homes?

- How do you think this level of access has changed since the economic growth began in Collin County?

- Which types of transportation services do you think are most helpful to residents of Collin County who need to access services since the economic growth began in Collin County?

- Describe the level of ease or difficulty in accessing services like doctors, schools, jobs, and homes as a Collin County resident.

What would you tell a someone who is considering moving to Collin County about the public transportation system?

What else do you want to tell us? 
Appendix E

Online Focus Group protocol for non-EJ population

Hello, my name is (name of researcher). You are logged in today for our discussion regarding Transportation Infrastructure in Collin County. We will begin by reviewing the informed consent together, and if you would like to continue participating in the research, we will ask for your verbal or written agreement to participate. (Researcher will read informed consent, share on screen, and ask for each participant to orally consent). We ask that all participants keep the information discussed in our session confidential although we cannot promise confidentiality. This is a reminder that you do not have to disclose your actual name or other identifying information and you can withdraw from participation at any time. This information will not be linked to you after the focus group.

Introductions

- Please introduce yourself using the psuedonym you selected when you joined the meeting.

Roles related to transportation

- How do you use public transportation systems in Collin County?

- How do you see your role as related to transportation infrastructure in Collin County? Are you a consumer or decision maker? Please describe.

Perspectives on Economic Growth

- How would you describe the economic growth in Collin County over the last 5 years? Has it been fast or slow, large or small, etc. Give examples of what you have observed?

Perspectives on Transportation Infrastructure

- How well do you think residents of Collin County can access services like doctors' offices, schools, jobs, and homes?

○ How do you think this level of access has changed since the economic growth began in Collin County?

- Which types of transportation services do you think are most helpful to residents of Collin County who need to access services since the economic growth began in Collin County?

- Describe the level of ease or difficulty in accessing services like doctors, schools, jobs, and homes as a Collin County resident.

What would you tell a someone who is considering moving to Collin County about the public transportation system?

What else do you want to tell us? 


\section{Transportation Research Study}
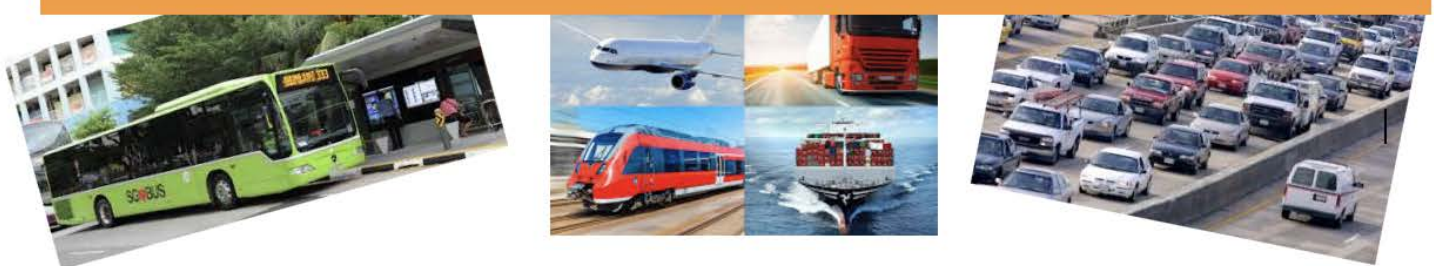

Be Part of an Important Research Study!

- Are you 18 and over?

- Do you live in Collin County?

- Do you speak English?

- Do you need assistance with transportation to school, work, home, or to the doctor?

If you answered YES to these questions, you may be eligible to participate in the transportation research study.

The purpose of this study is to better understand the level of access to important services in Collin County like healthcare, education, housing, and employment. Participants will receive a $\$ 5$ Walmart gift card.

This study is being conducted at the location displaying this flyer.
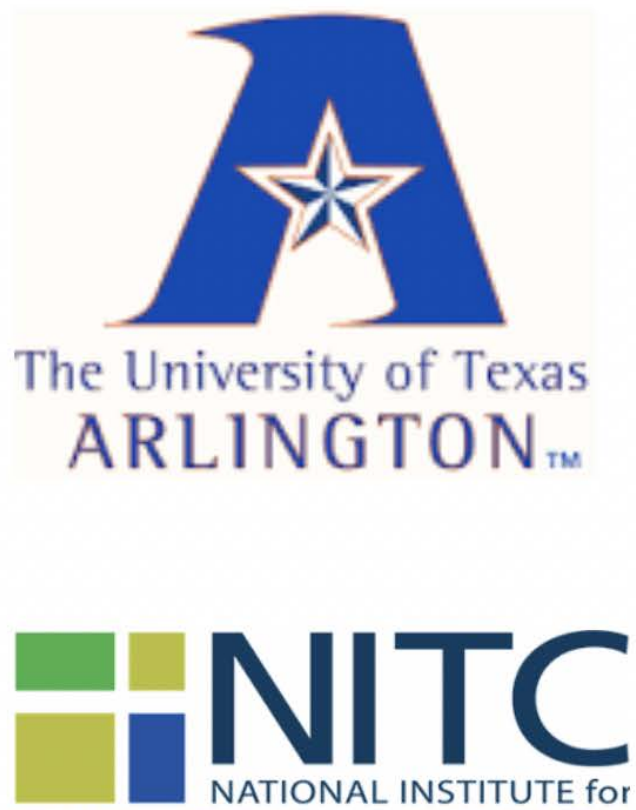

TRANSPORTATION and COMMUNITIES

Please let the research staff member know that you are interested in this study or call

Jandel Crutchfield at (225)- 2061072 if you have any questions. 
Appendix G

Qunerica Sarvey Seftwar.

10/2n/12 10:00 AM

Default Question Block

TITLE OF RESEARCH PROJECT

"Helping Environmental Justice Populations Maintain Access to Opportunities in a Boomtown: An Interdisciplinary, Mixed-Methods Approach to Addressing Infrastructure Needs

\section{RESEARCH TEAM}

Jandel Crutchfield, PhD, LCSW, 225-06-1072, jandel.crutchfield@uta_edu

Courtney Cronley, Phd, cronley@uta.edu

Kate Hyun, kate.hyun@ uta.edu

\section{IMPORTANT INFORMATION ABOUT THIS RESEARCH PROJECT}

The research team above is conducting a research study about transportation in Collin County, Texas. The purpose of this study is to better understand the level of access to important services in Collin County like healthcare, education, housing, and employment. You can choose to participate in this research study if you live in Collin County, Texas; speak and read English, are 18 years of age or older, and need transportation assistance to get access to services including healthcare, housing, education, and employment.

You might want to participate in this study if you want to contribute your perspective to a scientific study involving transportation needs in Collin County. However, you might notwant to participate in this study if you do not have the time to complete a 30 minute survey.

This study has been reviewed and approved by an Institutional Review Board (IRB). An IRB is an ethics committee that reviews research with the goal of protecting the rights and welfare of human research subjects. Your most important right as a human subject is informed consent. You should take your time to consider the information provided by this form and the research team, and ask questions about anything you do not fully understand before making your decision about participating. 


\section{TIME COMMITMENT}

You are being asked to participate in one (1) online survey. The survey will last no longer than 30 minutes. These will be conducted in April and May of 2019.

\section{RESEARCH PROCEDURES}

If you decide to participate in this research study, this is the list of activities that we will ask you to perform as part of the research:

1. Read through this Informed Consent and talk with the research team to make sure that any questions you may have are answered; then make your choice about whether to participate.

2. If you agree to participate, you will be asked to complete a 30 minute aurvey online.

3. As a research participant, we are asking you to participate in one (1) online survey. The researcher will meet with you to complete the survey. It will contain questions about your perception of transportation infrastructure in Collin County and how this impacts your access to services like housing. healthcare, education, and employment.

\section{POSSIBLE BENEFITS}

If you take part in this project, there may or may not be a direct benefit to you. We hope that your answers will influence the recommendations made to the Collin County Homeless Coalition. This is also an opportunity for you to make your voice heard and to express any concerns regarding transportation in Collin County.

\section{POSSIBLE RISKS/DISCOMFORTS}

Some questions and responses may be sensitive. If you feel upset or uncomfortable, please tell the researcher. We will provide you with a counselor or a referral in case you are upset during or after the study. You have the right to refuse to answer any question and to quit the study at any time with no consequence.

\section{COMPENSATION}

You will be given one (1) $\$ 5$ gift card to Walmart for your time. This will be given to you immediately following the completion of the survey.

The Internal Revenue Service (IRS) considers all payments made to research subjects to be taxable income. Your personal information, including your name, address, and social security number, may be acquired from you and provided to UTA's accounting office for the purpose of payment. If your total payments for the year exceed $\$ 600.00$, UTA will report this information to the IRS as income and you will receive a Form 1099 at the end of the year. If you receive less than $\$ 600.00$ total for payments in a year, you are personally responsible for reporting the payments to the IRS.

\section{ALTERNATIVE OPTIONS}

There are no alternative options offered for this study.

\section{CONFIDENTIALITY}


The research team is committed to protecting your rights and privacy as a research subject. All paper and electronic data collected from this study will be stored in a secure location on the UTA campus and/or a secure UTA server for at least three (3) years after the end of this research. The recordings will be kept with the other electronic data in a secure UTA Box account for the duration of the study.

The results of this study may be published and/or presented without naming you as a participant. The data collected about you for this study may be used for future research studies that are not described in this consent form. If that occurs, an IRB would first evaluate the use of any information that is identifiable to you, and confidentiality protection would be maintained.

While absolute confidentiality cannot be guaranteed, the research team will make every effort to protect the confidentiality of your records as described here and to the extent permitted by law. In addition to the research team, the following entities may have access to your records, but only on a need-to-know basis: the U.S. Department of Health and Human Services and the FDA (federal regulating agencies), the reviewing IRB, and sponsors of the study.

\section{CONTACT FOR QUESTIONS}

Questions about this research study or reports regarding an injury or other problem may be directed to Jandel Crutchfield, jandel.crutchfield@uta.edu, 225-206-1072 Any questions you may have about your rights as a research subject or complaints about the research may be directed to the Office of Research Administration; Regulatory Services at 817-272-3723 or regulatoryservices@uta.edu.

\section{CONSENT}

By clicking yes below, you are confirming that you understand the study's purpose, procedures, potential risks, and your rights as a research subject. By agreeing to participate, you are not waiving any of your legal rights. You can refuse to participate or discontinue participation at any time, with no penalty or loss of benefits that you would ordinarily have. Please click "yes" below if you are at least 18 years of age and voluntarily agree to participate in this study.

Do you wish to participate in this study?
YES
NO 
In the past year, how often have you used the following modes of transportation to get around Collin County?

\begin{tabular}{|c|c|c|c|c|c|c|c|}
\hline & Never & Once & $\begin{array}{l}\text { Once a } \\
\text { Month }\end{array}$ & $\begin{array}{l}2 \text { times } \\
\text { per year }\end{array}$ & $\begin{array}{l}2 \text { times } \\
\text { per } \\
\text { month }\end{array}$ & Weekly & Dally \\
\hline DART & 0 & 0 & $\mathrm{O}$ & 0 & 0 & $\mathrm{O}$ & $\mathrm{O}$ \\
\hline Public Bus & 0 & 0 & 0 & 0 & 0 & 0 & $\mathrm{O}$ \\
\hline $\begin{array}{l}\text { Rideshare (Uber, Lytt, } \\
\text { etc) }\end{array}$ & 0 & 0 & 0 & 0 & 0 & 0 & $\mathrm{O}$ \\
\hline Carshare (zlpper) & 0 & 0 & 0 & 0 & 0 & $O$ & $\mathrm{O}$ \\
\hline Personal vehicle & 0 & 0 & 0 & 0 & 0 & 0 & 0 \\
\hline Blcycle & 0 & 0 & $O$ & 0 & 0 & 0 & $\mathrm{O}$ \\
\hline Wa:k & 0 & 0 & 0 & 0 & 0 & 0 & 0 \\
\hline Other & 0 & 0 & 0 & 0 & 0 & $\mathrm{O}$ & 0 \\
\hline
\end{tabular}

Please select your preferred mode of transportation to get to the following destinations?

\begin{tabular}{|c|c|c|c|c|c|c|c|c|}
\hline & $\begin{array}{c}\text { Public } \\
\text { bus }\end{array}$ & $\begin{array}{l}\text { Ride } \\
\text { share } \\
\text { (Uber, } \\
\text { Lyett, } \\
\text { etc.) }\end{array}$ & $\begin{array}{c}\text { Car } \\
\text { shave } \\
\text { (Zp } \\
\text { Car) }\end{array}$ & $\begin{array}{c}\text { Train } \\
\text { (DART) }\end{array}$ & Blcyle & Walking & $\begin{array}{c}\text { Personal } \\
\text { car }\end{array}$ & N/A \\
\hline Work & 0 & $O$ & $O$ & 0 & $O$ & $O$ & $O$ & 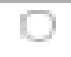 \\
\hline School & 0 & 0 & 0 & 10 & 0 & 0 & 0 & 0 \\
\hline Childcare & 0 & 0 & 0 & 10 & 0 & 0 & 0 & 10 \\
\hline Grocery shopping & 0 & 0 & 0 & 10 & 0 & 0 & 0 & 0 \\
\hline Park & 0 & 0 & 0 & 0 & 0 & 0 & 0 & 10 \\
\hline Entertainment & 0 & 0 & $O$ & 10 & 0 & 0 & $O$ & 0 \\
\hline Rellglous/speritual & 0 & 0 & 0 & 10 & 0 & 0 & $O$ & 10 \\
\hline Medical appointments & 0 & 0 & 0 & 10 & 0 & 0 & 0 & 10 \\
\hline Other & 0 & 0 & 0 & 0 & 0 & 0 & $\mathrm{O}$ & 0 \\
\hline
\end{tabular}


Please select your typica/mode of transportation to get to the following destinations?

\begin{tabular}{|c|c|c|c|c|c|c|c|c|}
\hline & $\begin{array}{l}\text { Puble } \\
\text { bus }\end{array}$ & $\begin{array}{l}\text { Ride } \\
\text { share } \\
\text { (Uber, } \\
\text { Lytt, } \\
\text { etc.) }\end{array}$ & $\begin{array}{l}\text { Car } \\
\text { share } \\
\text { (Zp } \\
\text { Car) }\end{array}$ & $\begin{array}{c}\text { Train } \\
\text { (DART) }\end{array}$ & Blcycle & Walking & $\begin{array}{c}\text { Personal } \\
\text { car }\end{array}$ & $\mathbf{N} / \mathbf{A}$ \\
\hline Work & 0 & $O$ & $\mathrm{O}$ & 10 & $O$ & 0 & 0 & 0 \\
\hline School & 0 & 0 & 10 & 0 & 0 & 0 & 0 & 10 \\
\hline Childcare & 0 & 0 & 0 & 0 & 0 & 0 & 0 & 0 \\
\hline Grocery shopping & 0 & 0 & 10 & 0 & 0 & 0 & 0 & 10 \\
\hline Park & 0 & 0 & $\mathrm{O}$ & $\mathrm{O}$ & 0 & 0 & 0 & 10 \\
\hline Entertalnment & 0 & 0 & $\mathrm{O}$ & $\mathrm{O}$ & 0 & 0 & 0 & 10 \\
\hline Rellglous/splittual & 0 & 0 & 0 & 0 & 0 & 0 & 0 & 10 \\
\hline Medical appointments & 0 & $O$ & 0 & 0 & 0 & 0 & 0 & 10 \\
\hline Other & 0 & 0 & 0 & 10 & 0 & 0 & 0 & 0 \\
\hline
\end{tabular}

What are some of the barriers for you to using public transit (e.g., DART, bus) in Collin County? (Please select all that apply.)
Costs
II Inconvenlence
Wait times
$\square$ Access points
Safety
Lack of knowledge
Preter not to use
$\square$ Other

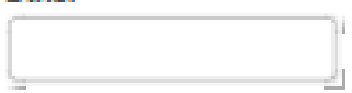

How would you describe the economic growth in Collin County over the past 10 years?

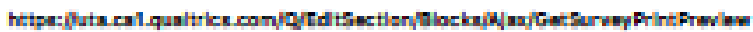

Page 5 at 9 


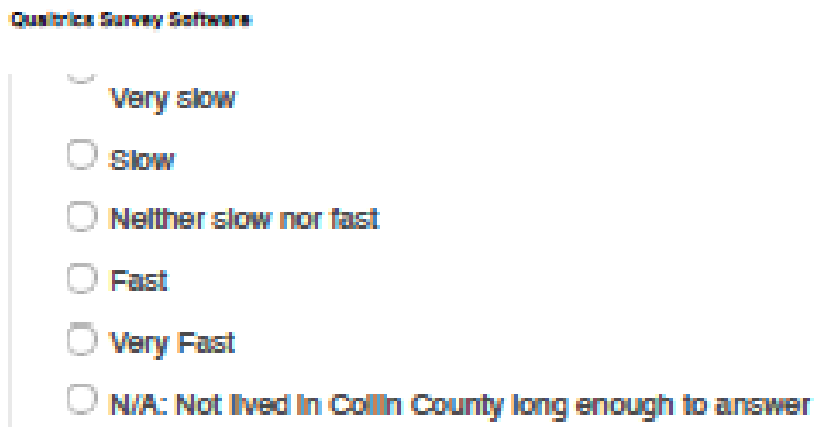

How effective is public transit (DART, bus) in Collin County for getting to the following destinations?

\begin{tabular}{|c|c|c|c|c|c|c|}
\hline & $\begin{array}{c}\text { Not } \\
\text { Eflectlve }\end{array}$ & $\begin{array}{l}\text { Sightly } \\
\text { Efrective }\end{array}$ & Neutral & $\begin{array}{l}\text { Moderately } \\
\text { Eflectlve }\end{array}$ & $\begin{array}{c}\text { Very } \\
\text { Ellective }\end{array}$ & NVA \\
\hline Home & 0 & O & 0 & 0 & 0 & 0 \\
\hline School & 0 & 0 & 0 & 0 & 0 & 0 \\
\hline Work & 0 & 0 & 0 & 0 & 0 & 0 \\
\hline Doctors visits & 0 & $\mathrm{O}$ & 0 & 0 & 0 & 0 \\
\hline Recreational activitles & 0 & 0 & 0 & 0 & & 0 \\
\hline Shopplng & 0 & $\mathrm{O}$ & 0 & 0 & 0 & 0 \\
\hline
\end{tabular}

\section{What is your gender?}

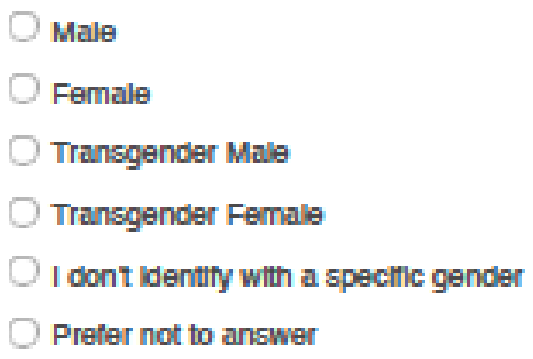

How old are you? 
Never marrled

Choose not to answer

What is your employment status?

Unemployed, by choice

Unemployed, not by cholce

Part-time employed, by choice

Part-time employed, not be cholce

Full-time employed, one job

Full-time employed, two jobs

Choose not to answer

What is your highest level of education?

Less than a high school degree

High school degree or equivalent

Assoclates degree

some college

College degree

Master's degree

Doctoral degree

choose not to answer

If interested, please provide your name and email address below so we can follow up with you about participating in a focus group. 


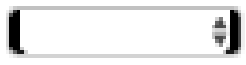

How long have you lived in Collin County?

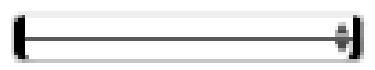

How many children under the age of 18 live with you?

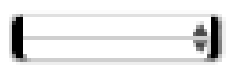

To what ethno-racial group do you belong?

African-American

Aslan/Pacific Islander

European-American

Latino

Mult-raclal.

Nattve American

other

Preter not to answer

What is your marital status?
Marrled
Widowed
Divorced
Separated 